\title{
Keeping inequality at home: the genesis of gender roles in housework ${ }^{*}$
}

\author{
J. Ignacio Giménez-Nadal, University of Zaragoza and BIFI \\ Lucia Mangiavacchi, University of Perugia and IZA \\ Luca Piccoli, University of Trento and IZA
}

\begin{abstract}
This article studies how gender role attitudes are transmitted from parents to their children by examining the intrahousehold division of housework time. The Russia Longitudinal Monitoring Survey (RLMS-HSE) is used to analyse the time devoted by parents to housework during their children's late childhood or adolescence and that of the same children once they marry. The results suggest that a greater proportion of housework performed by mothers during childhood is related to a persistence in gender inequality in their children's future families. These gender norms are perpetuated directly to sons through a lower amount of housework performed and indirectly to daughters through the choice of a partner that replicates her father role model. An analysis of the possible transmission mechanisms proposed by the literature suggests a prominent role of the parental role model, according to which children tend to reproduce the situation they experienced during childhood. These findings shed light on the persistence of parental behaviour across generations, underlining the key role of fathers, and contribute to the debate about how gender inequality is transmitted over time.
\end{abstract}

Keywords: Gender Norms, Gender Role Attitudes, Housework, Intergenerational Transfers.

JEL Codes: D13, J16, J22.

\footnotetext{
* This article benefited from funding from the Spanish Ministry of Economics and Competitiveness (Grant numbers ECO2015-63727-R and ECO2012-34828). We are grateful for comments and suggestions from the editor, Michele Pellizzari, and two anonymous referees. The article also benefited from comments received from Shoshana Grossbard, Daniel Hamermesh, Alberto Molina, Yu Zhu and participants at the $28^{\text {th }}$ EALE conference in Ghent, the XXXI AIEL conference in Trento, the third SITES/IDEAS conference in Florence and the $42^{\text {nd }}$ Symposium of the Spanish Economic Association in Barcelona.
}

Email addresses: ngimenez@unizar.es (J.I. Gimenez-Nadal), lucia.mangiavacchi@unipg.it (L. Mangiavacchi, corresponding author), luca.piccoli@unitn.it (L. Piccoli). 


\section{Introduction}

This article analyses how gender role attitudes and gender norms are transmitted from parents to children, linking the gender distribution of housework between parents with the distribution of housework in their children's families approximately ten years later, when the children marry or start cohabiting.

The previous literature suggests that cultural traits and values are important determinants of persistent inequality in the gender division of housework and female labour force participation (e.g. Fernández et al., 2004; Fernández and Fogli, 2009; Alesina et al., 2013). The persistence of cultural beliefs regarding the role of women in society depends on the fact that the family is an important determinant of individual attitudes, as predicted by theoretical economic models on the intergenerational transmission of values (Bisin and Verdier, 2000; Doepke and Zilibotti, 2017). However, empirical evidence with direct observation of parents and children behaviour related to gender role attitudes is scarce. For instance, Farré and Vella (2013) and Haaland et al. (2018) found that cultural attitudes regarding the role of women in the family and labour market are transmitted across generations. Farré and Vella (2013) based their results on individuals' opinions towards gender roles, finding that the mother's view of the role of women in the labour market and the family is strongly correlated with the views of her sons and daughters. Haaland et al. (2018) use registry data to link current individual employment data with parental employment in the past, analysing the transmission of employment gender gap as a measure of gender norms. Similarly, we base our analysis on the link between children's and parents' behaviours. However, we measure attitudes towards gender roles using the female's share of housework within a couple observed at the individual level for parents and their children's own families. ${ }^{1}$

Previous findings on the intrahousehold allocation of housework time have consistently reported that women specialize in household tasks (e.g., Aguiar and Hurst, 2007; Gimenez-Nadal and Sevilla, 2012; Giannelli et al., 2012). This evidence is found in most countries, independent of their economic, geographic, and demographic characteristics, which may indicate that attitudes towards the gender distribution of housework may persist across generations as a cultural trait. If this is true, parents' roles in housework during their children's early ages is

\footnotetext{
${ }^{1}$ Sevilla (2010) and Gimenez-Nadal et al. (2012) showed the relation between gender attitudes and norms and intrahousehold time-use distribution.
} 
crucial in determining gender inequalities in the housework time of the following generation, with implications for women's labour market outcomes (Hersch and Stratton, 2002).

Interest in the analysis of the intergenerational transmission of gender roles through the observation of housework gender division is not new in the economic literature (Cardoso et al., 2010; Álvarez and Miles, 2012; Solaz and Wolff, 2015; Gimenez-Nadal et al. 2018). However, the existing literature is based on cross-sectional data observing children when they live in their parents' households and not when they form their own families as adults. In contrast, we exploit a unique dataset, the Russia Longitudinal Monitoring Survey (RLMS-HSE), which follows children throughout adulthood and marriage, allowing their gender role attitudes to be measured as the female's share of domestic work. We compute the parental division of housework in the 1994 to 1998 waves of the RLSM-HSE and introduce this division as a predictor of children's housework time when they live as part of a couple in the 2006 to 2009 waves. Since our estimations are performed with a sample of young married adults, we control for selection into marriage similarly to Choo and Siow (2006) and Dahl (2010).

In line with Farré and Vella (2013) and Haaland et al. (2018), our results suggest that gender role attitudes are persistent across generations: the greater gender inequality in housework (i.e., a higher value for the mother to father share of housework) is in parents' households, the greater it is in children's own families, with a slightly larger coefficient for sons. The amount of domestic work performed during childhood and the overall amount of domestic work in the family of origin are not relevant in explaining the gender distribution of domestic work in children's own families. We interpret these findings as evidence that the transfer of gender roles is mediated by a parental role model process more than through habit acquisition or preference transmission.

Our contribution to the literature is threefold. First, we contribute to the research on the intergenerational transmission of gender role attitudes and gender norms by estimating the longitudinal impact of parental division of time use during late childhood on the gender division of housework in young adult couples. Our results complement prior research analysing the transmission of beliefs and preferences (Bisin and Verdier, 2001; Fernández et al., 2004; Fernández and Fogli, 2009; Doepke and Zilibotti, 2017; Aina and Nicoletti, 2018) and social norms and attitudes (Dohmen et al., 2012; Farré and Vella, 2013; Rodríguez-Planas and Nollenberger, 2018; Rodríguez-Planas and Sanz-de-Galdeano, 2019). Second, the information available in our data allows us to empirically test the three transmission mechanisms identified in previous literature: parental role model (Akerlof and Kranton, 2000), habit acquisition (Loureiro et al., 2010) and preference transmission (Bisin and Verdier, 2001). Third, we 
contribute to the literature on intergenerational economic mobility over the long term (Bowles and Gintis, 2002; Clark and Cummins, 2015; Güell et al., 2018) by focusing on the role of gender and family formation in the process of the intergenerational transmission of economic status.

The rest of the article is organized as follows. Section 2 establishes the conceptual framework based on prior results. Section 3 describes the data, and Section 4 outlines the empirical strategy. Section 5 presents the main findings, and Section 6 summarizes our main conclusions.

\section{Related literature on the intergenerational transmission of gender norms}

To explain the associations between parents' and children's distribution of housework time, three possible mechanisms have been identified by previous studies: the parental role model, the intergenerational transmission of preferences for housework and the acquisition of habits during childhood. The parental role model, derived from the model by Akerlof and Kranton (2000) on gender identity, supports the existence of gender norms about what a man or a woman should or should not do, with a social cost of deviating from the expected behaviour. Under these circumstances, parents may transmit these role models to their children so that they will conform to the social norms (Farré and Vella, 2013; Mancini et al., 2017; Haaland et al., 2018), including gender responsibilities for household tasks. In the case of intergenerational transmission of preferences, the economic literature has extensively shown that parents influence the child's preference (Bisin and Verdier, 2001; Fernández et al., 2004; Doepke and Zilibotti, 2017) and attitude formation (Dohmen et al., 2012; Nollenberger et al., 2016; Aina and Nicoletti, 2018). Similarly, parents may transmit to their children their tastes for housework, for instance, preferences for a clean house or homemade food, and for the gendered distribution of this housework. Alternatively, it could be that children's behaviour is the result of the repetition of housework tasks that can lead to the creation of habits, as previously documented in other domains of parental behaviours such as health or risky behaviours (Loureiro et al., 2010; Mangiavacchi and Piccoli, 2018; Pieroni and Lanari, 2018).

Three main methodologies have been used in prior research to identify intergenerational transmission of attitudes or behaviours. The first follows an epidemiological approach, exploiting cultural differences among immigrants of different origins living in the same country and estimating the impact of cultural family background on gender role attitudes (Alesina et al., 2013), labour market outcomes (Fernández et al., 2004; Fernández and Fogli, 2009) and risky behaviours (Rodrígez-Planas and Sanz-de-Galdeano, 2019). The second approach analyses the current values of both parents and children. The disadvantage of this approach is that causal identification can be hampered by both unmeasured factors and reverse causality issues. Existing 
studies on the intergenerational correlation in the allocation of time have adopted this methodology, using cross-sectional data to examine children's time spent on domestic activities when they still lived with their parents. Cardoso et al. (2012) find evidence of a positive relationship between the time allocations of parents and youngsters in France, Germany, and Italy. In a sample of Spanish families, Álvarez and Miles (2012) find a significant positive correlation between a more egalitarian parental allocation of housework and a less asymmetrical distribution of domestic chores between sons and daughters. Furthermore, in a sample of French couples, Solaz and Wolff (2015) find a positive relationship between child's and parents' housework time. For the UK, Gimenez-Nadal et al. (2018) show positive intergenerational correlations in housework hours, indicating that the more time parents devote to housework, the more their children do. Additionally, prior evidence has shown a gender differential in the intergenerational transmission of attitudes, as the association between mother (father) and son is different from the association between mother (father) and daughter (Álvarez and Miles, 2012; Solaz and Wolff, 2015).

A third methodology for dealing with identification issues links the past behaviour of parents with the current behaviour or attitudes of their children. Following this approach, Farré and Vella (2013) link the gender role attitudes of mothers in 1979 with those of their children in 1994 in the U.S, and Haaland et al. (2018) use a similar strategy for Norway using registry data. This article follows the same strategy, exploiting longitudinal data from Russia and linking the gender distribution of housework between heterosexual parents with the distribution of housework in their children's families approximately ten years later when the children marry or start cohabiting.

In Russia, the previous literature dealing with couples' labour supply and gender roles (Kalugina et al., 2009; Lacroix and Radtchenko, 2011; Giannelli et al., 2013) supports the stability of traditional gender norms despite radical changes in the education system and labour market following the transition to a market economy. Kalugina et al. (2009) and Lacroix and Radtchenko (2011) analyse the evolution of couples' labour supply during transition periods and just after the 1998 financial crisis, while Giannelli et al. (2013) estimate a simultaneous equations system for the intrahousehold allocation of market work, housework, and child care between 2006 and 2009. These studies show substantial intrahousehold inequality in housework and care time. Chiappori et al. (2018) show that there are no relevant changes over the period under analysis also on the determinants of union formation and dissolution, and the patriarchal model 
of the family with early age marriages is not eroded during the transition period (see also Philipov and Jasilioniene, 2008).

\section{Data, sample selection and main variables}

We use the Russia Longitudinal Monitoring Survey (RLMS-HSE), conducted by the Higher School of Economics and ZAO Demoscop, together with the Carolina Population Center, University of North Carolina at Chapel Hill and the Institute of Sociology RAS. The data cover approximately 5,000 households, 12,000 adults, and 2,000 children per wave. The survey collects time use data for both adults and children in rounds V to VIII and XV to XVIII, spanning from 1994 to 1998 and from 2006 to 2009, respectively. One of the key issues in the existing literature on the intergenerational transmission of housework distribution is the lack of data on the family of origin and the same children once they become adults (Cardoso et al., 2010; Álvarez and Miles, 2012; Gimenez-Nadal et al. 2018). The RLMS-HSE fills this gap since it is a sufficiently long panel to allow the observation of families with children in the first four waves and the same children once they reach adulthood and form a couple approximately ten years later. The data structure is thus individual-based and composed of two panel periods separated by a seven-year gap. Since we link parental behaviour during childhood with children's behaviour when they become adults, the main dataset is a panel of young adults who are married or cohabiting, observed in rounds XV to XVIII, with matched information on parents and their own behaviour when they were children, observed in rounds V to VIII.

The main outcome of interest, gender role attitudes in young couples, refers to the second panel period (2006 to 2009) and is measured by two types of variables: i) the female's share of time spent on housework activities within the couple and ii) the amount of time devoted to housework activities traditionally performed by women. The first is computed by dividing the female's amount of time devoted to housework by the sum of both partners' time. The second is constructed from the daily amount of time devoted to purchasing food, cooking, cleaning house, and doing laundry. ${ }^{2}$ Housework activities typically performed by men, such as gardening and house repairs, are excluded from the analysis because they were collected using a different

\footnotetext{
${ }^{2}$ In rounds XV-XVIII, individuals were asked to answer the following question: "In the last 30 days, how many minutes per day did you spend on the following activities:" separately for week days and weekends. The listed activities included purchasing food goods, preparing food, washing dishes, cleaning rooms, doing laundry (including ironing). Answers to these questions are aggregated to represent the time devoted to each activity per week, and then the hours of housework as the sum of these specific activities. We thus rely on stylized questions about the time devoted to several activities rather than a time-use diary. This poses a limitation in comparison to specific time-use surveys, as diary-based estimates tend to be more reliable and accurate than estimates derived from direct questions (Bonke, 2005). Still, the unique advantage of having repeated time-use data for the same individuals over a long time span clearly counterbalances this limitation.
} 
categorization in the two panel periods, making them not comparable over time. Thus, we focus on activities traditionally performed by women (Hersch and Stratton, 2002; Grossbard et al., 2014). For adult children, the average female's share of housework is approximately 0.79 , while the weekly hours are approximately 13 for housework, 2.7 for purchasing food, 5.5 for cooking, 2.6 for cleaning and 2.3 for doing laundry (see the first panel of Table A1 in the Appendix).

The key explanatory variable for the study is the average share of traditional housework (traditionally performed by women) performed by the mother in 1994-98 (and the same share for purchasing food, cooking, cleaning and doing laundry). ${ }^{3}$ This variable is assumed to capture the transmission of gender norms from parents to children through a parental role model effect. The average female's share of traditional housework for mothers is 0.87 (see the second panel of Table A1), which is only slightly larger than that of their children. Another possibly important transmission mechanism is through habit acquisition, which is accounted for by the amount of housework performed during childhood in 1994-98 (on average, 2.3 hours per week). Finally, a third possible mechanism is through the transmission of preferences. For instance, if a child is raised in a tidy, clean house, it is likely that he/she will try to reproduce a similar situation once he/she forms his/her own family. This mechanism is taken into account by including the average amount of housework performed by adults in the family of origin (on average, 27.3 hours per week).

The third panel of Table A1 reports the descriptive statistics of a set of contemporaneous characteristics of the young adult and his/her family in 2006-09. This set includes gender, age and its square, having any chronic illness, age in 1994 (to control for possible cohort effects), the number of children, the number of working age adults and elders in the household, regions of residence, and being of non-Russian nationality. The set also includes variables to control for specific determinants of the amount of housework supplied by family members derived from marriage market theory (Grossbard, 2015). The first variable is the sex ratio, an indicator of how favourable a local marriage market is to women. Specifically, we include the fertile women ratio, i.e., the number of women aged 18 to 45 years over the number of men aged 18 to 65 years computed at the primary sampling unit (PSU) level for each round. In addition to marriage market

\footnotetext{
${ }^{3}$ In rounds V-VIII, individuals were asked to answer the following questions: "How much time in the last 7 days did you spend looking for and purchasing food items?" (purchasing food), "How much of your time did this (preparing food and washing dishes) occupy in the last 7 days" (cooking), "How much of your time did this (cleaning, remodelling and repairing furniture or household appliances) occupy in the last 7 days" (cleaning) and "How much of your time did this (doing laundry, ironing, and repairing or making clothes for your family) occupy in the last 7 days" (doing laundry).
} 
conditions, another relevant aspect to account for is compensating differentials, i.e., the fact that one partner may need to "compensate" the other for a relevant difference in some characteristics. For instance, if the wife is more educated than her husband, she may need to do less housework as a compensation. To capture such an aspect, we include in the set of control variables the relative education of the wife with respect to the husband (as the ratio of wife's years of schooling divided by the sum of both partners' years of schooling). Finally, as the 1997 financial crisis may have led to substantial and long-lasting consequences for local labour markets, including by gender, we control for the change in the PSU-level employment rate from the average 1994-98 value by gender.

The fourth panel of Table A1 describes some parental characteristics observed in the years from 1994-98. The characteristics include both parents' average work status for the observed rounds and their education levels in the form of dummies for primary and tertiary education.

The statistics reported in Table A1 are computed on the main estimation sample, which is composed of 226 individuals and 588 observations, for which the selection process is as follows. The panel of young adults (four waves, from 2006 to 2009) is composed of 16,399 individuals and 48,233 observations, of which only those recorded in the child questionnaire at least once in the first panel period (1994-98) are retained. The sample is thus reduced to 1,654 individuals and 5,016 observations. In addition, only adults (at least 18 years old) and married or cohabiting individuals are retained, which, along with a few missing values in some variables, reduces the sample to 236 individuals and 588 observations. ${ }^{4}$

This large reduction from the original sample may raise doubts regarding its representativity. As the representativeness of the sample is guaranteed only for the cross-sectional component, an analysis is performed on round XVI, which had the most observations of the selected sample. The population of interest in this work consists of young couples who recently married or started cohabiting. Restricting the general individual sample from round XVI to individuals who are young (18 to 30 years) and married, we obtain our reference sample of young couples, which is composed of 1151 individuals. The requirement that further restricts the sample, possibly generating selection bias from attrition, is that individuals must also be observed in rounds $\mathrm{V}$ to VIII, when they were still living with their parents, and recorded in the child questionnaire, so

\footnotetext{
${ }^{4}$ It is worth noting that although the sample is composed of married or cohabiting individuals, only one member of the couple is retained, the one who was observed as a child. In fact, we take advantage of a sampling choice specific to this survey, i.e., that children are still followed when they leave the original household and form their own household. However, there is no way to know the amount of domestic work of their current partners' parents in 1994-98.
} 


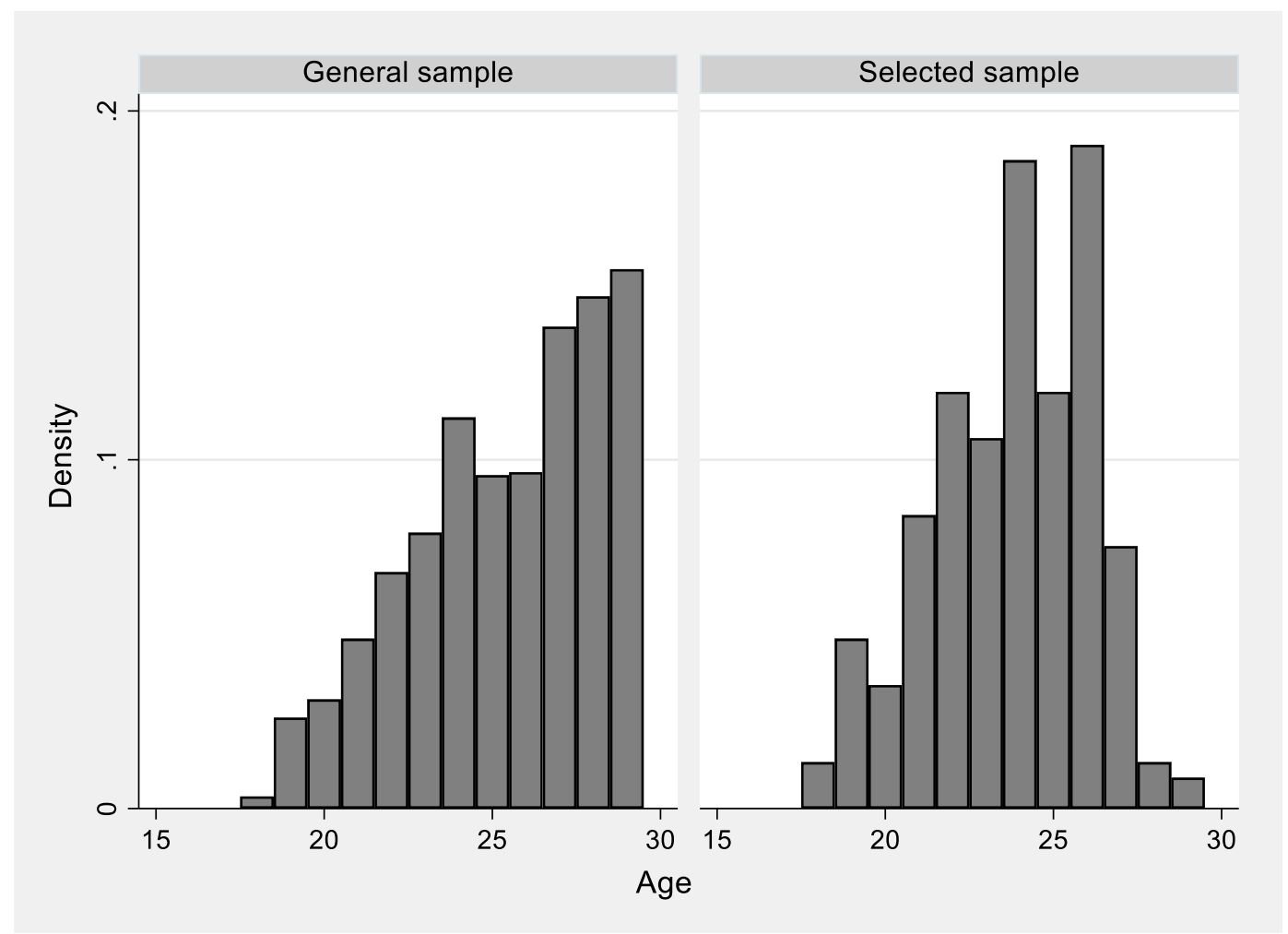

Figure 1: Distribution of age in the general and selected samples.

they need to be younger than 15 years of age in the first panel period. This further restricted sample is composed of 226 individuals in round XVI.

This kind of selection is likely to generate a different distribution of age in the two groups. Indeed, while one can generally expect that the probability of being married increases with age, as verified in the general sample (see left panel of Figure 1), the requirement of being recorded in the child questionnaire in the first panel period poses an upper limit on observed age in the selected sample. This is why a sharp drop in the proportion of individuals aged 27 years and above is observed in the right panel of Figure 1. It is also expected that other variables directly related to age, such as number of children, will show significant differences as well.

Table 1 shows the descriptive statistics of the relevant individual characteristics, along with a two-sample t-test with unequal variances for the difference between the general and selected sample. The selected sample is composed of significantly younger individuals, with fewer children and elders living in the household. Nevertheless, all other variables of interest, particularly female's share of housework, hours per week of housework and work, probability of being currently working and monthly wages, are not significantly different in the two samples. These results suggest that for the objective of our study, the sample selection imposed should not produce large biases in our results, implying that the results could be safely interpreted referring 
to the population of interest, i.e., young couples. Nevertheless, in the empirical analysis a Heckman correction model is still applied to formally account for possible sample selection bias.

Table 1: T-tests for differences in the sample means for individual characteristics

\begin{tabular}{|c|c|c|c|c|c|c|}
\hline \multirow[b]{2}{*}{ Variable } & \multicolumn{2}{|c|}{ General } & \multicolumn{2}{|c|}{ Selected } & \multicolumn{2}{|c|}{ Test-t } \\
\hline & Mean & Std. Dev. & Mean & Std. Dev. & Diff. & P-val. \\
\hline Female's share of housework & 0.784 & 0.213 & 0.785 & 0.216 & 0.001 & 0.934 \\
\hline Total housework hours per week & 13.524 & 11.773 & 14.198 & 11.810 & 0.674 & 0.434 \\
\hline Purchasing food hours per week & 2.764 & 2.500 & 3.075 & 3.117 & 0.310 & 0.163 \\
\hline Cooking hours per week & 5.521 & 5.476 & 5.728 & 5.174 & 0.207 & 0.588 \\
\hline Cleaning hours per week & 2.681 & 3.035 & 2.786 & 3.020 & 0.105 & 0.636 \\
\hline Doing laundry hours per week & 2.717 & 3.600 & 2.748 & 3.351 & 0.031 & 0.901 \\
\hline Working hours per week & 34.858 & 22.211 & 33.502 & 22.419 & 1.357 & 0.406 \\
\hline Currently working & 0.772 & 0.420 & 0.752 & 0.433 & 0.020 & 0.525 \\
\hline Log of monthly wage & 6.693 & 4.009 & 6.234 & 4.099 & 0.459 & 0.123 \\
\hline Age* & 25.427 & 2.824 & 23.761 & 2.358 & 1.666 & 0.000 \\
\hline Chronic illness & 0.308 & 0.462 & 0.323 & 0.469 & 0.015 & 0.669 \\
\hline Number of children* & 0.809 & 0.699 & 0.699 & 0.617 & 0.110 & 0.017 \\
\hline Number of elders* & 0.176 & 0.450 & 0.115 & 0.347 & 0.061 & 0.024 \\
\hline Number of working age family members & 2.441 & 1.216 & 2.566 & 1.372 & 0.125 & 0.203 \\
\hline Number of individuals & \multicolumn{2}{|c|}{1151} & \multicolumn{2}{|c|}{226} & & \\
\hline
\end{tabular}

* The difference between the general and selected sample is significant at 5\% according to a two-sample t-test with unequal variances.

Another possible concern in analysing intergenerational relations of housework time is that differences in the gender division of housework between children and their parents may arise because they are observed at different stages of the life cycle. In our sample, young adults are aged between 18 and 32 years old, and 23\% are married or becoming married during the period. Mothers and fathers, on the other hand, are on average 44 and 46 years old, respectively, in the years from 1994-98. Figure 2 plots the probability density functions of the time spent on traditional housework by married daughters in 2006-09 and their mothers in 1994-98. The amount of housework among mothers in 1994-98 has a similar distribution to that of their daughters, although the latter is shifted towards smaller amounts. On the other hand, there seems to be a generational shift towards a more egalitarian distribution of housework time for the later generations. This is confirmed by Figure 3, which plots female's share of housework time for adult children and their mothers. Mother's share is more concentrated around one, while a shift towards a more egalitarian distribution of housework is observed for their daughters. 


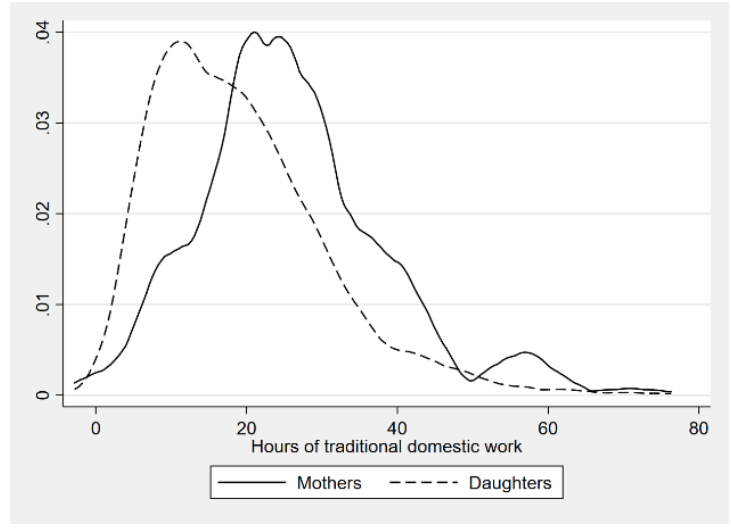

Figure 2 Distribution of housework hours, mothers and daughters

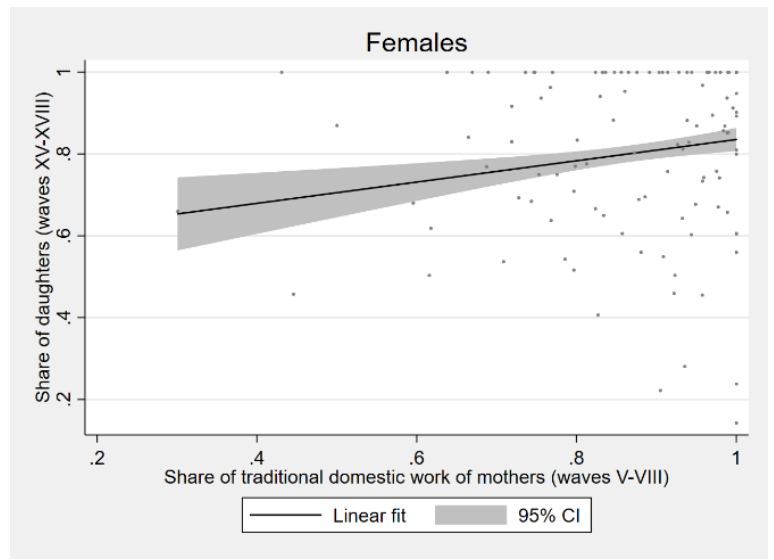

Figure 4 Correlation between mother's and daughter's share of housework

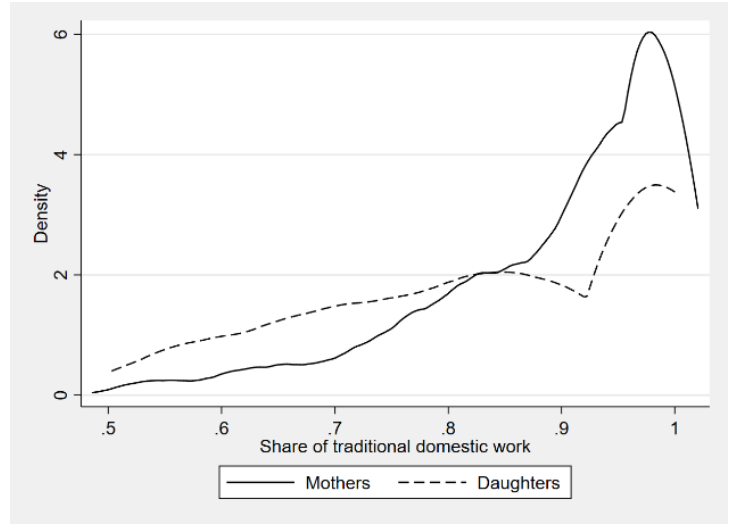

Figure 3 Couple distribution of housework, mothers and daughters

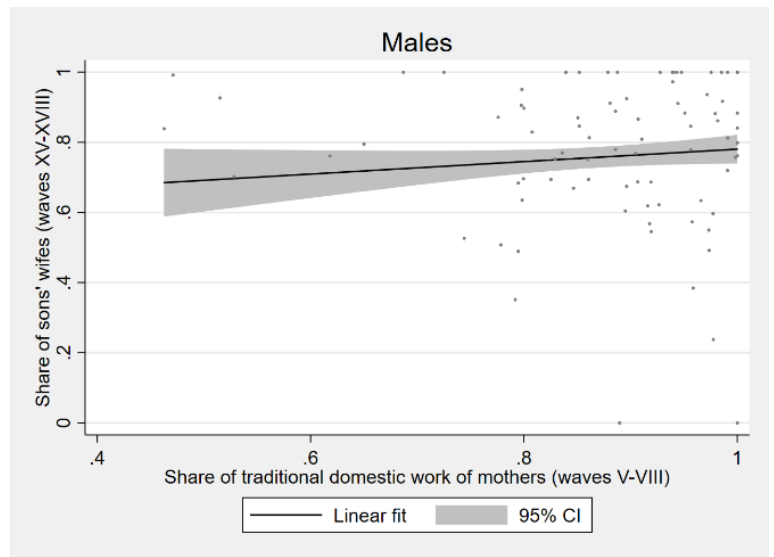

Figure 5 Correlation between mother's and son's wives' share of housework

Finally, the raw relationship between parents' division of housework and that of their children, the main objective of the study, is summarized in Figures 4 and 5. Both figures present a scatter plot of the share of housework among parents and their adult children in their own families, and a linear fit for the relationship, separately for sons and daughters. Figure 4 plots the relationship between mother's share of housework and their married daughters' share, while Figure 5 depicts the relationship between mother's share of housework and their sons' wives' share. Both graphs show positive relationships, although the coefficient is significant only for daughters.

\section{Empirical strategy}

Considering that the outcomes of interest are time-variant, the panel data structure is maintained to take advantage of panel data estimation techniques. However, the explanatory variables that pertain to the first period are time-invariant in the second period, as they are computed using their average value for each individual. This includes mother's share of housework during 
childhood, our main explanatory variable, which is thus time-invariant. As a consequence, the fixed effects (FE) estimator is ruled out, and the only possibility is to use random effects (RE) estimators (Cameron and Trivedi, 2005).

The objective of the estimation is to relate mother's share of housework with children's division of household labour, and the main explanatory variable of interest, mother's proportion of housework, is reasonably exogenous with respect to the distribution of housework in the son's or daughter's independent household. However, a proper identification of the effect may still be hampered by three empirical difficulties. First, some of the independent variables measured in years 2006-09, used as controls in the main model, may suffer from correlation with the individual effect. This can be corrected by applying an extension of the RE model, which allows for correlation between the individual effects and the regressors (Mundlak, 1978). The second possible source of estimation bias relies on the censored nature of the dependent variable. Indeed, female's share of housework is naturally bounded between 0 and 1 , and binding in a relevant proportion of observations (approximately 26\%), especially on the upper bound. This is addressed by applying a two-limit RE Tobit (Wooldridge, 2010).

A last concern about the robustness of our results is the possible presence of sample selection bias. Indeed, to explore the transmission of gender norms in terms of distribution of housework, we need to select a sample of married individuals who were observed as children while living with their parents in 1994-98. Because these individuals are relatively young in 2006-09, there may be selection bias (see Section 3). To deal with the possibility of sample selection bias, we apply a Heckman correction model jointly estimating an RE Probit regression for marriage with the main regressions of interest. The exclusion restrictions used in the marriage equation are i) body mass index (BMI) z-score, with the idea that individuals who are farther from the average BMI may be less likely to be married, especially at young age (Chiappori et al., 2012), while not directly influencing the share of housework; ii) average age at first marriage at the PSU level (computed over years 2000-2012), with the idea of capturing local social norms about marriage age; and iii) standard deviation of age at first marriage at the PSU level (computed over years 2000-2012), with the idea that the more individuals are deviating from the social norm, the lower the associated cost should be. Age at first marriage has been previously used in the literature to address the issue of selection into marriage (Choo and Siow, 2006; Dahl, 2010), and it adapts well to the Russian marriage market (also Philipov and Jasilioniene, 2008; Chiappori et al. 2018). Provided that these exclusion restrictions are significant in explaining the probability of marriage, this allows us to account for the correlation of both the individual effects and the idiosyncratic 
components of the regressions. Descriptive statistics for these three variables are available in the last panel of Table A1.

More formally, denoting by $s_{i t}$ female's share of total spousal amount of housework for individual $i$ in time $t$, the corresponding linear RE model is specified as:

(1) $s_{i t}=\alpha_{i}+x_{i t}^{\prime} \beta+w_{i}^{\prime} \gamma+\varepsilon_{i t}$,

where $\alpha_{i}$ is the individual effect, $x_{i t}$ is a set of time-varying variables recorded during years 2006-09, and $w_{i}$ is a set of variables that are registered in 1994-98, capturing individuals' childhood variables and parental characteristics, ${ }^{5}$ and $\varepsilon_{i t} \sim \mathcal{N}\left(0, \sigma_{\varepsilon}^{2}\right)$ is the idiosyncratic component. Mother's share of housework when the individual was a child, the main explanatory variable of interest, is included in matrix $\mathrm{w}_{\mathrm{i}}$.

When considering the censored nature of female's share of housework, which has two limits at 0 and 1, the model can be specified as a two-limit RE Tobit (see Wooldridge, 2010, ch.17.7 p. 703), i.e.,

(2) $s_{i t}^{*}=\alpha_{i}+x_{i t}^{\prime} \beta+w_{i}^{\prime} \gamma+\varepsilon_{i t}$,

where $s_{i t}^{*}$ is a latent variable that relates to the observed female's share of housework as

(3) $s_{i t}= \begin{cases}0 & \text { if } s_{i t}^{*} \leq 0 \\ s_{i t}^{*} & \text { if } 0<s_{i t}^{*}<1 \\ 1 & \text { if } s_{i t}^{*} \geq 1\end{cases}$

The RE Tobit model can be estimated by maximum likelihood (ML) under the assumption that $\alpha_{i} \sim \mathcal{N}\left(0, \sigma_{\alpha}^{2}\right)$. The panel level likelihood for this model function reads as

$$
l_{i}=\int_{-\infty}^{\infty} \frac{e^{-\alpha_{i}^{2} / 2 \sigma_{\alpha}^{2}}}{\sqrt{2 \pi} \sigma_{\alpha}}\left\{\prod_{t=1}^{n_{i}} F\left(s_{i t}, \Delta_{i t}\right)\right\} d \alpha_{i},
$$

Where $\Delta_{i t}=\alpha_{i}+x^{\prime}{ }_{i t} \beta+w^{\prime}{ }_{i} \gamma$, and

$$
F\left(s_{i t}, \Delta_{i t}\right)= \begin{cases}\Phi\left(\frac{s_{i t}-\Delta_{i t}}{\sigma_{\varepsilon}}\right) & \text { if } s_{i t}=0 \\ \left(\sqrt{2 \pi} \sigma_{\varepsilon}\right)^{-1} e^{-\left(s_{i t}-\Delta_{i t}\right)^{2} /\left(2 \sigma_{\varepsilon}^{2}\right)} & \text { if } 0<s_{i t}<1 \\ 1-\Phi\left(\frac{s_{i t}-\Delta_{i t}}{\sigma_{\varepsilon}}\right) & \text { if } s_{i t}=1\end{cases}
$$

\footnotetext{
${ }^{5}$ In order to reduce the incidence of measurement errors, these variables are averaged during the period 1994-98 and used in the regression as time-invariant variables.
} 
When Mundlak's (1978) extension is applied, either in a linear RE or an RE Tobit specification (Brown et al., 2013), the individual effect is specified as

(4) $\alpha_{i}=\bar{x}_{i}^{\prime} \pi+\xi_{i}$,

where $\bar{x}_{i}^{\prime}$ is the vector of the longitudinal mean of time-varying variables $x_{i t}$ for each individual. In this way, the possible correlation of time-varying variables with the individual effect is captured by coefficients $\pi$, which represent the between effect of these variables, while coefficients $\beta$ capture the within effect.

When considering the possible bias arising from selection into marriage, an RE Probit equation with Mundlak correction is introduced to estimate the probability of being married or cohabiting,

(5) $c_{i t}^{*}=v_{i}+z_{i t}^{\prime} \theta+x_{i t}^{\prime} \beta+w^{\prime}{ }_{i} \gamma+\epsilon_{i t}$

(6) $\quad c_{i t}= \begin{cases}1 & \text { if } c_{i t}^{*} \geq 0 \\ 0 & \text { if } c_{i t}^{*}<0\end{cases}$

(7) $v_{i}=\bar{z}_{i}^{\prime} \mu+\bar{x}_{i}^{\prime} \pi+\xi_{i}$,

where $c_{i t}^{*}$ is the latent variable expressing the probability that individual $i$ is married or cohabiting at time $t, c_{i t}$, and $z_{i t}^{\prime}$ is a set of exclusion restrictions that guarantees the identification of the model. The model can be estimated by ML assuming that the idiosyncratic component is iid standard normal $\left(\epsilon_{i t} \sim \mathcal{N}(0,1)\right)$, and the individual effect is iid normally distributed $\left(v_{i} \sim \mathcal{N}\left(0, \sigma_{v}^{2}\right)\right)$.

To account for selection into marriage, the probability of the marriage equation is estimated jointly with the outcome of interest (either linear RE, RE Tobit or Mundlak) using the cmp Stata command (Roodman, 2011), which allows arbitrary correlations between both the idiosyncratic components $\left(\rho_{\varepsilon \epsilon}\right)$ and the individual effects $\left(\rho_{\alpha \nu}\right.$ or $\left.\rho_{\xi v}\right)$.

Because it is possible that the impact of mother's share of housework on female's share of housework in the child's family is different based on the gender of the child, the aforementioned analysis is also performed by gender. In particular, for the outcome equation, the gender effect is computed only for mother's share of housework, the hours of housework performed during childhood and the per adult amount of housework in the family of origin, while for the selection into market, all explanatory variables have gender-specific effects. 
In addition to female's share of housework, other outcomes of interest are tested. In particular, total hours of housework and hours of single housework activities, i.e., purchasing food, cooking, cleaning and making laundry, and participation in the labour force.

The specification used for modelling hours of housework, specific activities and hours of work is an RE Tobit estimator with the Mundlak extension and correction for selection into marriage, estimated as for female's share of housework, except that there is no upper bound for the dependent variable, i.e.,

(8) $h_{i t}^{*}=\alpha_{i}+x_{i t}^{\prime} \beta+w_{i}^{\prime} \gamma+\varepsilon_{i t}$,

(9) $\quad h_{i t}= \begin{cases}h_{i t}^{*} & \text { if } h_{i t}^{*}>0 \\ 0 & \text { if } h_{i t}^{*} \leq 0\end{cases}$

where $h_{i t}$ stands for the hours spent on these activities, and the explanatory variables are the same as those for female's share of housework, except that the mother's share refers to the same activity as the outcome. For instance, hours of cleaning are explained by mother's share of cleaning. These analyses are run by gender with the same specification used for female's share of housework. The estimation is run jointly for the four housework activities and the equation for selection into marriage.

\section{Results}

As detailed in Section 2, the previous literature on intergenerational transmission of gender norms identified three possible mechanisms for the transmission of the distribution of time use between parents and children: the parental role model (Akerlof and Kraton, 2000, Mancini et al., 2017), the acquisition of habits (Loureiro et al., 2010; Rodríguez-Planas and Sanz-de-Galdeano, 2019), and the intergenerational transmission of preferences for housework (Bisin and Verdier, 2001).

A formal test of these transmission mechanisms can be performed using the empirical strategies proposed in Section 4, provided that suitable proxies for the outcome of interest and the three mechanisms are available. Due to the characteristics of the data used, it is possible to test all of these transmission mechanisms. The main dependent variable used is female's share of time spent on housework activities traditionally performed by women within the couple. The first mechanism can be proxied by including mother's share of housework in waves V-VIII. The second possible transmission channel is the acquisition of habits, on which the previous literature on intergenerational transmission of housework gender division is founded (Álvarez and Miles, 2012; Gimenez-Nadal et al. 2018). To test this channel, it is possible to use as a proxy the amount 
of housework performed during childhood in waves V-VIII. The third mechanism assumes that there is an intergenerational transmission of preferences for housework. For instance, if a child is raised in a tidy, clean house, it is likely that he/she will try to reproduce a similar situation once he/she forms his/her own family. This mechanism can be taken into account by including the average amount of housework performed by adults in the family of origin in waves V-VIII.

Table 2: Intergenerational transmission of female's share of housework: Linear RE

$\begin{array}{lccccccc}\text { Coefficients of interest } & \text { Model 1 } & \text { Model 2 } & \text { Model 3 } & \text { Model 4 } & \text { Model 5 } & \text { Model 6 } \\ \text { Mother's share of housework in waves V-VIII } & & & & & & & \\ & & & & & & & \\ & (0.083) & (0.086) & (0.087) & (0.084) & (0.084) & (0.083) \\ \text { Average weekly hours of housework in waves V-VIII } & 0.012^{*} & 0.008 & 0.005 & 0.008 & 0.008 & 0.008 \\ & (0.006) & (0.007) & (0.007) & (0.007) & (0.007) & (0.006) \\ \text { Per adult hours of housework in the family of origin } & 0.000 & 0.000 & 0.000 & -0.001 & -0.001 & -0.001 \\ & (0.001) & (0.001) & (0.001) & (0.001) & (0.001) & (0.001)\end{array}$

\section{Control variables}

Parents' characteristics

Yes Yes Yes Yes Yes

Adult characteristics

Adult family characteristics

Cohort

Geographic and ethnic characteristics

$\begin{array}{cccc}\text { Yes } & \text { Yes } & \text { Yes } & \text { Yes } \\ & \text { Yes } & \text { Yes } & \text { Yes } \\ & & \text { Yes } & \text { Yes } \\ & & & \text { Yes }\end{array}$

\begin{tabular}{lcccccc} 
R-squared & 0.027 & 0.047 & 0.061 & 0.147 & 0.147 & 0.194 \\
Observations & 645 & 645 & 645 & 588 & 588 & 588 \\
Number of individuals & 265 & 265 & 265 & 236 & 236 & 236 \\
\hline
\end{tabular}

For all specifications, the dependent variable is female's share of housework. The coefficients of the explanatory variables of interest are reported in the top panel of the table. Model 1 does not include other control variables. Model 2 adds selected parents' characteristics recorded in waves V-VIII: average work status, primary education and tertiary education. Model 3 adds individual characteristics: gender, age and its square, chronic illness, and currently working. Model 4 adds some family and marriage market characteristics: number of children, number of elders, number of working age adults, wife/husband education ratio and PSU-level fertile female ratio. Model 5 adds a control for possible cohort effects: age at wave V. Model 6 adds geographic and ethnic information: macro-regional dummies, the evolution of female and male labour force participation at the PSU level and being non-Russian. Full estimation results are presented in Table A.2.

$* * * \mathrm{p}<0.01, * * \mathrm{p}<0.05, * \mathrm{p}<0.1$. Cluster robust standard error in parentheses.

Table 2 reports a first set of results obtained using linear RE regressions with increasing sets of control variables to test the stability of the coefficients of the three variables of interest: Model 1 has no control variables besides the individual specific effect; Model 2 introduces the parental characteristics observed in waves V-VIII; Model 3 adds contemporaneous adult characteristics; Model 4 introduces contemporaneous family characteristics; Model 5 controls for cohort effects; and Model 6 adds geographical and ethnic characteristics. ${ }^{6}$

\footnotetext{
${ }^{6}$ The full list of control variables introduced in each model is reported in a note to Table 2.
} 
Table 3 Intergenerational transmission of female's share of housework: Other estimators

\begin{tabular}{|c|c|c|c|c|}
\hline & Model 7 & Model 8 & Model $9^{1}$ & Model $10^{1}$ \\
\hline \multicolumn{5}{|l|}{ Coefficients of interest } \\
\hline \multirow[t]{2}{*}{ Mother's share of housework in waves V-VIII } & $0.176^{* *}$ & $0.164 * *$ & $0.229 * * *$ & $0.216 * * *$ \\
\hline & $(0.077)$ & $(0.077)$ & $(0.078)$ & $(0.078)$ \\
\hline \multirow[t]{2}{*}{ Average weekly hours of housework in waves V-VIII } & 0.008 & 0.005 & 0.009 & 0.007 \\
\hline & $(0.006)$ & $(0.006)$ & $(0.007)$ & $(0.007)$ \\
\hline \multirow[t]{2}{*}{ Per adult hours of housework in the family of origin } & -0.000 & -0.000 & -0.001 & -0.000 \\
\hline & $(0.001)$ & $(0.001)$ & $(0.001)$ & $(0.001)$ \\
\hline \multicolumn{5}{|l|}{ By gender } \\
\hline \multirow[t]{2}{*}{ Female x Mother's share of housework in waves V-VIII } & $0.179 * *$ & $0.170^{* *}$ & $0.239 * * *$ & $0.231 * * *$ \\
\hline & $(0.081)$ & $(0.081)$ & $(0.060)$ & $(0.060)$ \\
\hline \multirow[t]{2}{*}{ Male x Mother's share of housework in waves V-VIII } & $0.191 * *$ & $0.169 * *$ & $0.239 * * *$ & $0.209 * *$ \\
\hline & $(0.083)$ & $(0.083)$ & $(0.061)$ & $(0.061)$ \\
\hline \multicolumn{5}{|l|}{ Test of the difference between gender coefficients ${ }^{2}$} \\
\hline Test value (chi2) & 0.18 & 0.00 & 0.00 & 0.18 \\
\hline p-value & 0.672 & 0.989 & 0.987 & 0.672 \\
\hline \multicolumn{5}{|l|}{ Model features } \\
\hline Selection into marriage & Yes & Yes & Yes & Yes \\
\hline Mundlak & & Yes & & Yes \\
\hline Tobit & & & Yes & Yes \\
\hline Pseudo R-squared ${ }^{2}$ & 0.258 & 0.281 & 0.209 & 0.227 \\
\hline Observations & 588 & 588 & 588 & 588 \\
\hline Number of individuals & 236 & 236 & 236 & 236 \\
\hline
\end{tabular}

For all specifications, the dependent variable is female's share of housework. Each specification includes all the control variables listed for Model 6 in Table 2, except gender when presenting the coefficient separately for males and females. Full estimation results are presented in Tables A. 3 and A. 4

Notes: 1. Coefficients and standard errors of the Tobit specifications are multiplied by the share of uncensored observations (which accounting for both lower and upper limit is 0.740 ) to be comparable with the linear coefficients; $\mathbf{2}$. The test contrasts that the difference in the coefficients for males and females is equal to zero. The statistic is distributed as a chi ${ }^{2}$ with 1 degree of freedom. 2. The pseudo R-squared refers to the joint estimation of the marriage and outcome equation, without genderspecific coefficients and computed according to McFadden's formula (one minus the ratio of the log likelihood for the full specification over the intercepts only one). The pseudo R-squared of the linear and Tobit specifications are not comparable, as the definition of the likelihood functions differs. In addition, they are not comparable with the R-squared of the linear RE regressions reported in Table 2 .

$* * * \mathrm{p}<0.01, * * \mathrm{p}<0.05, * \mathrm{p}<0.1$. Cluster robust standard errors in parentheses.

The results reported in Table 2 show that the estimated coefficients are quite stable. Including additional sets of covariates reduces only slightly the magnitude of the coefficient of mother's share of housework, with the largest reduction being observed once family characteristics are introduced. This is also the set of covariates that increases goodness of fit the most, as shown in the lower part of the table. Some missing observations for the education level of both partners also slightly reduce the number of observations in Models 4 to 6. Child's average weekly hours of housework in waves V-VIII and per adult hours of housework in the family of origin have negligible and non-significant coefficients, which scarcely vary across specifications. 
Table 3 reports the estimated coefficients of the three main variables of interest of the more sophisticated estimation techniques used to deal with the identification issues exposed in Section 4: the possible correlation between the individual effect and some time-varying covariates (Models 8 and 10), the censored nature of the dependent variable (Models 9 and 10) and a possible bias due to the selection of young married couples (Models 7 to 10). All these estimations are performed using the same set of control variables as in Model 6. The results show that the coefficient of mother's share of housework slightly decreases compared to Model 6 when correcting for both selection into marriage and the correlation between the individual effect and the covariates (Models 7 and 8).

Our preferred specification is Model 10 in Table 3, chosen based on a series of specification tests reported by Table A.5 in the Appendix, which confirms that panel estimators are preferred to pooled OLS, that the Mundlak extension to the linear RE should be applied, and that sample selection is at work. Additionally, OLS estimates are known to be inconsistent when the dependent variable is censored, and in the present sample, the proportion of censoring is approximately $26 \%$, which is quite relevant and suggests that misspecification bias could be nontrivial. The results reported in Table 3 suggest that correcting for the censored nature of the dependent variable reveals that the linear RE specifications suffer from underestimation bias. Indeed, the marginal effects of Models 9 and 10 are approximately 30\% larger than the coefficients of the linear RE specifications (Models 7 and 8, respectively), and this is because censoring mostly happens at 1 , the upper limit, when the female partner performs all the housework. This is the case for $25 \%$ of the sample, while the lower limit, i.e., when the male partner performs all the housework, occurs in only approximately $1 \%$ of the sample.

As presented in Section 4, the issue of selection into marriage, addressed with a joint estimation of selection into marriage and the outcome equations (see Section 4) with the presence of three exclusion restrictions in the marriage equation, BMI z-score, average age at first marriage at the PSU level, and standard deviation of age at first marriage at the PSU level, all significant at least at $5 \%$ and with the expected sign (see the last column of Table A.3).

The marginal effect of mother's share of traditional domestic work reported in Model 10 of Table 3 indicates that an increase in mother's share by 1 percentage point implies an increase in female's share in the children's household by 0.216 percentage points, with a significance level of $1 \%$, so there is an intergenerational transmission of at least one-fifth of the effect. On the other hand, the marginal effects of child's average hours of domestic work in waves V-VIII and of the per adult hours of domestic work in the family of origin are not significantly different from zero. 
This result implies that habit acquisition in performing housework during childhood and parental preferences for household production have minor roles with respect to the parental role model in determining the gender norms in children's own families. These findings imply that focusing on the contemporaneous correlation between parents' and children's housework time and assuming that acquired habits are persistent over the lifetime is a sensitive assumption made by the previous literature (Álvarez and Miles, 2012; 2016; Solaz and Wolff, 2015; Gimenez-Nadal et al. 2018). The analysis of the impact of mother's share of housework by gender of the child reveals that the transmission of gender norms is not specific, for instance, from mothers to daughters. While the coefficient for daughters is slightly larger than that for sons (see Table 3), the difference is not significantly different from zero. There can still be gender differences in the transmission process, as sharing involves both partners engaging in domestic work, and it is possible to observe only one partner's parents' behaviour. Thus, to further test possible differences in the transmission of gender roles in housework, we also investigate whether mother's share of domestic work has an impact on their son's and daughter's individual hours of housework, including by type of activity.

Table 4 shows the results of these additional estimations using the same sample selection used in the previous estimations (thus considering only married or cohabiting children) and applying the Mundlak-Tobit RE specification with correction for possible selection into marriage bias. ${ }^{7}$ Again, Table 4 reports only the coefficients of the three main variables of interest: mother's share of traditional housework, average weekly hours of housework performed during childhood, and per adult hours of housework in the family of origin (see Table A.6 for full estimation results). The dependent variables are the total amount of housework and, for the specific activities, hours spent purchasing food, cooking, cleaning, and doing laundry. Estimations are performed by gender of the child, and for the specific activities, a joint estimation of the marriage equation plus all four activities equations, allowing for arbitrary correlations between individual effects and idiosyncratic components of all equations.

Table 4: Weekly hours spent on domestic work and specific activities.

\begin{tabular}{|c|c|c|c|c|c|}
\hline & \multicolumn{5}{|c|}{ Hours of housework } \\
\hline & Total & $\begin{array}{c}\text { Purch. } \\
\text { food }\end{array}$ & Cooking & Cleaning & Laundry \\
\hline \multicolumn{6}{|l|}{ Daughter's hours } \\
\hline Mother's share of housework in waves V-VIII & 2.011 & $1.053 * *$ & 1.609 & $1.062 *$ & 1.347 \\
\hline
\end{tabular}




\begin{tabular}{|c|c|c|c|c|c|}
\hline & $(3.598)$ & $(0.426)$ & $(0.994)$ & $(0.644)$ & $(0.983)$ \\
\hline Average weekly hours of housework during childhood & $\begin{array}{c}0.405 \\
(0.358)\end{array}$ & $\begin{array}{c}0.149 * \\
(0.079)\end{array}$ & $\begin{array}{c}0.264 * \\
(0.143)\end{array}$ & $\begin{array}{l}0.240 * * \\
(0.104)\end{array}$ & $\begin{array}{c}0.334 * * * \\
(0.105)\end{array}$ \\
\hline Per adult hours of housework in the family of origin & $\begin{array}{c}0.062 \\
(0.041)\end{array}$ & $\begin{array}{c}0.015^{*} \\
(0.008)\end{array}$ & $\begin{array}{c}0.024 \\
(0.015)\end{array}$ & $\begin{array}{c}0.004 \\
(0.011)\end{array}$ & $\begin{array}{c}0.000 \\
(0.011)\end{array}$ \\
\hline \multicolumn{6}{|l|}{ Son's hours } \\
\hline Mother's share of housework in waves V-VIII & $\begin{array}{c}-12.165 * * * \\
(3.729)\end{array}$ & $\begin{array}{c}0.573 \\
(0.491)\end{array}$ & $\begin{array}{c}-7.069 * * * \\
(1.220)\end{array}$ & $\begin{array}{c}-4.288 * * * \\
(0.781)\end{array}$ & $\begin{array}{c}-6.935 * * * \\
(1.337)\end{array}$ \\
\hline Average weekly hours of housework during childhood & $\begin{array}{c}-0.541 \\
(0.358)\end{array}$ & $\begin{array}{c}-0.111 \\
(0.079)\end{array}$ & $\begin{array}{c}0.248 \\
(0.143)\end{array}$ & $\begin{array}{c}-0.124 \\
(0.104)\end{array}$ & $\begin{array}{c}-0.017 \\
(0.105)\end{array}$ \\
\hline Per adult hours of housework in the family of origin & $\begin{array}{c}-0.017 \\
(0.052)\end{array}$ & $\begin{array}{c}-0.002 \\
(0.012)\end{array}$ & $\begin{array}{c}-0.066 * * * \\
(0.025)\end{array}$ & $\begin{array}{c}-0.050 * * * \\
(0.019)\end{array}$ & $\begin{array}{c}0.017 \\
(0.024)\end{array}$ \\
\hline Pseudo R-squared ${ }^{2}$ & 0.098 & \multicolumn{4}{|c|}{0.369} \\
\hline Observations & 588 & \multicolumn{4}{|c|}{579} \\
\hline Number of individuals & 236 & \multicolumn{4}{|c|}{235} \\
\hline
\end{tabular}

This further analysis reveals interesting insights. For total hours of housework, the results show that an increase in mother's share of housework has smaller implications for sons in terms of household production when they are married or cohabiting, while the positive effect on daughters is not significantly different from zero. This result is in line with the findings of Álvarez and Miles (2012) and suggests that, in Russia, the parental role model is more relevant for sons, likely through father's example, as already shown in other domains (Loureiro et al., 2010; Pieroni and Lanari, 2018). It also suggests that while parental gender roles do not seem to directly affect the amount of housework performed by daughters, they still contribute to the new family's gender roles through the choice of husband, which will likely replicate the paternal role in the daughter's family of origin.

The analysis of specific activities provides further insights into the transmission mechanisms. Time spent cooking, cleaning, and doing laundry appear to drive the results for sons, while unlike Solaz and Wolff (2015), we find no statistically significant effects for purchasing food. For daughters, although the overall effect is non-significant, a positive impact is recorded for purchasing food and cleaning, so there is at least a partial direct effect.

A different pattern is observed for housework habit acquisition for specific activities as measured by the amount of housework performed during childhood. Habit acquisition seems to 
be important only for daughters for all activities, albeit mostly for cleaning and doing laundry. For sons, the results show no statistically significant effects of habit acquisition on the hours of any kind of domestic work. Regarding the transmission of preferences, for daughters, there is a weakly significant effect only for time spent purchasing food by other adults in the family of origin, while for sons, significant negative effects are observed for cooking and cleaning. Thus, there seems to be little evidence of intergenerational transmission of preferences for household production.

\section{Conclusions}

The intergenerational transmission of income, human capital, and preferences is a wellestablished research field in economics. However, only recently has attention been devoted to the intergenerational transmission of cultural beliefs on gender norms (Alesina et al., 2013; Farré and Vella, 2013; Haaland et al., 2018; Rodríguez-Planas and Sanz-de-Galdeano, 2019) and, in particular, to the relation between parents' and children's time devoted to housework (Cardoso et al., 2010; Álvarez and Miles, 2012; Gimenez-Nadal et al. 2018). Using the Russia Longitudinal Monitoring Survey, we analyse the relationship between parental division of housework during late childhood/adolescence and housework gender division approximately ten years later during marriage or cohabitation.

The results suggest that gender norms regarding the division of household tasks are persistent across generations, as a larger proportion of housework performed by the mother is related to a larger female proportion of housework in her child's family. Analysing the three main mechanisms proposed by the literature, the results indicate a prominent role of the parental role model (Akerlof and Kranton, 2000), according to which children tend to reproduce the situation they experienced during childhood or adolescence. Limited evidence is observed for the other two mechanisms: habit acquisition during childhood (Loureiro et al., 2010) and the transmission of preferences for household production (Bisin and Verdier, 2001). Indeed, the amount of domestic work children are required to do during late childhood is uncorrelated with the gender distribution of housework when they are adults, although for daughters, some positive correlation is observed for time spent on specific activities. Finally, a very minor role is observed for the transmission of preferences for household production, as the average amount of time spent by adults performing housework in the family of origin is uncorrelated with the gender division of housework. In substance, gender role models in the household division of labour are inherited by children through emulation of parental behaviour, independent of the amount of domestic work 
performed during adolescence and the average hours spent by adults performing housework in the family of origin.

The perpetuation mechanism of traditional gender roles is also analysed under the lens of the hours of housework supplied by young male adults. This additional analysis reveals that the transmission follows different patterns according to the gender of the child. There is a strongly negative relationship for sons and a non-significant relationship for daughters (although a small significant effect is found for specific activities, such as purchasing food and cleaning). This finding suggests that while the transmission of gender roles in the family is direct for sons, i.e., greater involvement by fathers increases the hours of domestic work among their sons. On the other hand, the effect on daughters is indirect and probably passes through the choice of a husband who replicates the role model of their father, who spent little time performing housework when they were children.

Greater involvement of mothers when their children are adolescents is thus related to lower involvement of sons and greater involvement of daughters in their own families ten years later, perpetuating gender inequality in housework division. This finding suggests that gender norms related to household tasks persist across generations, with likely consequences for policies aiming to increase female labour force participation. It is possible, in fact, that a weak response to such policies could be driven by the social cost of deviating from gender norms in the family. We show that the progressive shift towards less traditional gender roles among younger generations would be likely to progress more rapidly over time through a positive paternal example. Our results underline the importance of fathers as role models for their children, suggesting that policies aimed at increasing women's labour market participation should also consider men's traditional views of the household division of labour, favouring men's involvement in domestic tasks and reducing the individual cost of deviating from the gender social norm.

\section{COMPLIANCE WITH ETHICAL STANDARDS}

The authors declare that they have no conflicts of interest.

\section{REFERENCES}

Aina, C., and Nicoletti, C. (2018). "The intergenerational transmission of liberal professions," Labour Economics, 51, 108-120.

Aguiar, M., and Hurst, E. (2007). "Measuring trends in leisure: the allocation of time over five decades," Quarterly Journal of Economics, 122(3), 969-1006. 
Akerlof G.A., and Kranton, R.E. (2000). "Economics and Identity," Quarterly Journal of Economics, 115(3), 715-753.

Alesina, A., Giuliano, P., \& Nunn, N. (2013). "On the origins of gender roles: Women and the plough," The Quarterly Journal of Economics, 128(2), 469-530.

Álvarez, B., and Miles, D. (2012). 'Exploring the relationship between children's and parents' housework time in Spain," Review of Economics of the Household, 10(2), 299-318

Bisin, A., and Verdier, T. (2001). "The economics of cultural transmission and the dynamics of preferences". Journal of Economic theory, 97(2), 298-319.

Bonke, J. (2005). "Paid work and unpaid work: Diary information versus questionnaire information," Social Indicators Research, 70(3), 349-368.

Bowles, S., and Gintis, H. (2002). "The Inheritance of Inequality," Journal of Economic Perspectives, 16(3), 3-30.

Brown, S., Garino, G., and Taylor, K. (2013). "Household debt and attitudes toward risk," Review of Income and Wealth, 59(2), 283-304.

Cameron, A.C., and Trivedi, P.K. (2005). Microeconometrics: Methods and Applications. Cambridge University Press

Cardoso, A.R., Fontainha, E., and Monfardini, C. (2010). "Children's and parents' time use: empirical evidence on investment in human capital in France, Germany and Italy," Review of Economics of the Household, 8(4), 479-504.

Chiappori, P. A., Oreffice, S., \& Quintana-Domeque, C. (2012). "Fatter attraction: anthropometric and socioeconomic matching on the marriage market," Journal of Political Economy, 120(4), 659-695.

Chiappori, P. A., Radchenko, N., and Salanié, B. (2018). "Divorce and the duality of marital payoff," Review of Economics of the Household, 16(3), 833-858.

Choo, E., and Siow, A. (2006). "Who Marries Whom and Why," Journal of Political Economy, 114(1), 175-201.

Clark, G., and Cummins, N. (2015). "Intergenerational Wealth Mobility in England, 1858-2012. Surnames and Social Mobility,” Economic Journal 125(582), 61-85.

Dahl, G. B. (2010). "Early teen marriage and future poverty," Demography, 47(3), 689-718.

Doepke, M., and Zilibotti, F. (2017). "Parenting with style: Altruism and paternalism in intergenerational preference transmission," Econometrica, 85(5), 1331-1371.

Dohmen, T., Falk, A., Huffman, D., \& Sunde, U. (2011). "The intergenerational transmission of risk and trust attitudes". The Review of Economic Studies, 79(2), 645-677.

Farré, L., and Vella, F. (2013). "The intergenerational transmission of gender role attitudes and its implications for female labour force participation," Economica, 80(318), 219-247.

Fernández, R., and Fogli, A., (2009). "Culture: An empirical investigation of beliefs, work, and fertility," American Economic Journal: Macroeconomics, 1(1), 146-177.

Fernández, R., Fogli, A., and Olivetti, C., (2004). "Mothers and Sons: Preference Formation and Female Labor Force Dynamics," The Quarterly Journal of Economics, 119(4), 1249-1299.

Giannelli, G. C., Mangiavacchi, L., and Piccoli, L. (2012). "GDP and the value of family caretaking: how much does Europe care?," Applied Economics, 44(16), 2111-2131. 
Giannelli, G. C., Mangiavacchi, L., and Piccoli, L. (2013). "Do parents drink their children's welfare? Intra-household allocation of time between market labour, domestic work and child care in Russia," IZA Journal of Labor and Development, 2(13), 1-23.

Gimenez-Nadal, J.I., Molina, J.A., and Sevilla, A. (2012). "Social Norms, Partnerships and Children," Review of Economics of the Household, 10(2), 215-236.

Gimenez-Nadal, J.I, Molina, J.A., and Zhu, Y. (2018). "Intergenerational mobility of housework time in the United Kingdom," Review of Economics of the Household, 16(4), 911-937.

Giménez-Nadal, J.I., and Sevilla, A. (2012). "Trends in time allocation: A cross-country analysis," European Economic Review, 56(6), 1338-1359.

Grossbard, S. (2015) The Marriage Motive: A Price Theory of Marriage, Springer-Verlag New York.

Grossbard, S., Gimenez-Nadal, J.I., and Molina, J.A. (2014). "Racial Intermarriage and Household Production," Review of Behavioral Economics, 1(4), 295-347.

Güell, M., Pellizzari, M., Pica, G., and Rodríguez Mora, J. V. (2018). "Correlating social mobility and economic outcomes," The Economic Journal, 128(612), F353-F403.

Haaland, V. F., Rege, M., Telle, K., and Votruba, M. (2018). "The intergenerational transfer of the employment gender gap," Labour Economics, 52, 132-146.

Hersch, J., and Stratton, L. (2002). "Housework and Wages," Journal of Human Resources, $37(1), 217-229$.

Kalugina, E., Sofer, C., and Radtchenko, N. (2009). "Intra-household inequality in transitional Russia," Review of Economics of the Household, 7(4): 447-471.

Lacroix, G., and Radtchenko, N. (2011). "The changing intra-household resource allocation in Russia," Journal of Population Economics, 24(1), 85-106.

Loureiro, M. L., Sanz-de-Galdeano, A., and Vuri, D. (2010). "Smoking habits: like father, like son, like mother, like daughter?." Oxford Bulletin of Economics and Statistics, 72(6), 717743.

Mancini, A.L., Monfardini, C. and Pasqua, S. (2017). "Is a good example the best sermon? Children's imitation of parental reading," Review of Economics of the Household, 15(3), 965993.

Mangiavacchi, L., and Piccoli, L. (2018). "Parental alcohol consumption and adult children's educational attainment." Economics \& Human Biology, 28, 132-145.

Mundlak, Y. (1978). "On the Pooling of Time Series and Cross Section Data," Econometrica, 46(1), 69-85.

Nollenberger, N., Rodríguez-Planas, N. and Sevilla, A. (2016). "The Math Gender Gap: The Role of Culture," American Economic Review, 106(5), 257-61.

Philipov, D., and Jasilioniene, A. (2008). "Union formation and fertility in Bulgaria and Russia: A life table description of recent trends," Demographic Research, 19, 2057-2114.

Pieroni, L. and Lanari, D. (2018). "The Role of Fathers in the Criminal Careers of Juvenile in Italy," Journal of Demographic Economics, vol. 84(4), 419-445.

Rodríguez-Planas, N., and Nollenberger, N. (2018). "Let the girls learn! It is not only about math... it's about gender social norms," Economics of Education Review, 62(C), 230-253. 
Rodríguez-Planas, N., and Sanz-de-Galdeano, A. (2019). "Intergenerational transmission of gender social norms and teenage smoking," Social Science \& Medicine, 222, 122-132.

Roodman, D. (2011). "Estimating fully observed recursive mixed-process models with cmp." Stata Journal, 11(2), 159-206.

Sevilla, A. (2010). "Household division of labor and cross-country differences in household formation rates," Journal of Population Economics, 23(1), 225-249.

Solaz A., and Wolff, F.C. (2015). "Intergenerational Correlation of Domestic Work: Does Gender Matter?," Annals of Economics and Statistics, 117/118, 159-184.

Woodridge, J. M. (2010). Econometric Analysis of Cross Section and Panel Data, MIT Press. 


\section{Appendix A - Full Tables}

Table A1: Descriptive statistics

\begin{tabular}{lrrrr}
\hline & Mean & Std. Dev. & Min. & Max. \\
\hline Dependent variables & & & & \\
Female' share of housework & 0.790 & 0.202 & 0 & 1 \\
Housework hours per week & 13.09 & 10.88 & 0 & 60.17 \\
Purchasing food hours per week & 2.714 & 2.426 & 0 & 16.50 \\
Cooking hours per week & 5.480 & 5.370 & 0 & 28.17 \\
Cleaning hours per week & 2.655 & 2.896 & 0 & 16.00 \\
Doing laundry hours per week & 2.330 & 2.900 & 0 & 21.50 \\
Working hours per week & 33.480 & 20.913 & 0 & 105 \\
Currently unemployed & 0.226 & 0.419 & 0 & 1 \\
Log of wage rate & 3.790 & 0.853 & 0.712 & 6.44 \\
& & & & \\
Time use variables in 1994-98 & & & & \\
Mother's share of housework & 0.869 & 0.133 & 0.301 & 1 \\
Mother's share of purchasing food time & 0.791 & 0.266 & 0 & 1 \\
Mother's share of cooking time & 0.884 & 0.147 & 0.182 & 1 \\
Mother's share of cleaning time & 0.830 & 0.197 & 0.160 & 1 \\
Mother's share of doing laundry time & 0.958 & 0.102 & 0.294 & 1 \\
Average weekly hours of housework in waves V-VIII & 2.280 & 1.598 & 0 & 10.5 \\
Per alt & 27.330 & 13.914 & 85.435
\end{tabular}

Per adult hours of housework in the family of origin

$27.330 \quad 13.914$

$3 \quad 85.435$

\section{Adult children variables in 2006-09}

Gender (1=male)

Age

Age squared

0.398

0.490

24.36

2.54

599.7

123.0

Chronic illness

0.301

0.459

Age in 1994

12.781

2.457

Number of children

0.748

0.613

Number of elders

0.090

0.304

Number of working age members

2.529

Education ratio of the couple: female / (male + female)

0.456

1.383

Fertile women ratio

0.650

0.136

Housework of family members (minus self) per working age adult

5.814

0.115

region 1- Metropolitan areas: Moscow and St. Petersburg

0.039

4.931

region 2 - Northern and North Western

0.066

0.194

region 3 - Central and Central Black-Earth

0.228

0.249

region 4 - Volga-Vaytski and Volga Basin

0.156

0.420

region 5 - North Caucasian

0.131

0.364

region 6 - Ural

0.194

0.338

region 7 - Western Siberian

0.100

0.396

region 8 - Eastern Siberian and Far Eastern

Non-Russian nationality

Female employment ratio changes from rounds V-VIII

Male employment ratio changes from rounds V-VIII

0.085

0.301

0.077

0.279

1.050

0.266

0.994

0.172

0.144

$\begin{array}{ll}0 & 1\end{array}$

$18 \quad 32$

$324 \quad 1024$

$0 \quad 1$

$\begin{array}{ll}5 & 19\end{array}$

$\begin{array}{ll}0 & 3\end{array}$

$\begin{array}{ll}0 & 2\end{array}$

$\begin{array}{ll}0 & 7\end{array}$

$\begin{array}{rr}0 & 1\end{array}$

$0.418 \quad 0.920$

$\begin{array}{ll}0 & 27.938\end{array}$

$0 \quad 1$

$0 \quad 1$

$0 \quad 1$

$\begin{array}{ll}0 & 1\end{array}$

$\begin{array}{ll}0 & 1\end{array}$

$\begin{array}{ll}0 & 1\end{array}$

$\begin{array}{ll}0 & 1\end{array}$

Parents variables in 1994-98

Average father's work status (in each wave 1=work)

Mother's highest completed grade is in primary education

Father's highest completed grade is in primary education

(7)




\section{Exclusion restrictions for selection into marriage}

$\begin{array}{lrrrr}\text { Body mass index (BMI) Z-score } & 0.286 & 1.062 & -1.867 & 4.653 \\ \text { Average age at first marriage (by PSU for years 2000-12) } & 25.625 & 1.449 & 23.273 & 30.198 \\ \text { Standard deviation of age at first marriage (by PSU for years 2000-12) } & 7.68 & 2.420 & 4.128 & 13.551 \\ & & & & \\ \text { Number of individuals } & 226 & & & \end{array}$


Table A.2: Intergenerational transmission of female's share of housework: Linear RE - Full estimations

\begin{tabular}{|c|c|c|c|c|c|c|c|c|c|c|c|c|}
\hline \multirow[b]{2}{*}{ VARIABLES } & \multicolumn{2}{|c|}{ Model 1} & \multicolumn{2}{|c|}{ Model 2} & \multicolumn{2}{|c|}{ Model 3} & \multicolumn{2}{|c|}{ Model 4} & \multicolumn{2}{|c|}{ Model 5} & \multicolumn{2}{|c|}{ Model 6} \\
\hline & coef & se & coef & se & coef & se & coef & se & coef & se & coef & $\mathrm{se}$ \\
\hline Mother's share of housework in waves V-VIII & $0.239 * * *$ & $(0.083)$ & $0.236 * * *$ & $(0.086)$ & $0.242 * * *$ & $(0.087)$ & $0.193 * *$ & $(0.084)$ & $0.192 * *$ & $(0.084)$ & $0.182^{* *}$ & $(0.083)$ \\
\hline Average weekly hours of housework in waves V-VIII & $0.012 *$ & $(0.006)$ & 0.008 & $(0.007)$ & 0.005 & $(0.007)$ & 0.008 & $(0.007)$ & 0.008 & $(0.007)$ & 0.008 & $(0.006)$ \\
\hline Per adult hours of housework in the family of origin & 0.000 & $(0.001)$ & 0.000 & $(0.001)$ & 0.000 & $(0.001)$ & -0.001 & $(0.001)$ & -0.001 & $(0.001)$ & -0.001 & $(0.001)$ \\
\hline Average father's work status in waves V-VIII (in each wave $1=$ =work) & & & $-0.077 *$ & $(0.042)$ & $-0.082 *$ & $(0.044)$ & -0.049 & $(0.045)$ & -0.049 & $(0.045)$ & -0.039 & $(0.043)$ \\
\hline Average mother's work status in waves V-VIII (in each wave $1=$ =work) & & & -0.048 & $(0.032)$ & $-0.053 *$ & $(0.031)$ & -0.031 & $(0.033)$ & -0.031 & $(0.033)$ & -0.018 & $(0.031)$ \\
\hline Mother's highest completed grade is in primary education & & & $0.071 *$ & $(0.039)$ & $0.080 *$ & $(0.041)$ & 0.030 & $(0.042)$ & 0.030 & $(0.042)$ & -0.008 & $(0.035)$ \\
\hline Father's highest completed grade is in primary education & & & 0.011 & $(0.026)$ & 0.006 & $(0.027)$ & 0.011 & $(0.023)$ & 0.011 & $(0.023)$ & 0.016 & $(0.023)$ \\
\hline Mother's highest completed grade is in tertiary education & & & -0.015 & $(0.029)$ & -0.015 & $(0.029)$ & -0.039 & $(0.027)$ & -0.039 & $(0.027)$ & -0.021 & $(0.028)$ \\
\hline Father's highest completed grade is in tertiary education & & & 0.007 & $(0.032)$ & 0.004 & $(0.033)$ & 0.009 & $(0.031)$ & 0.008 & $(0.031)$ & 0.004 & $(0.030)$ \\
\hline Gender (1=male $)$ & & & & & $-0.052 * *$ & $(0.024)$ & -0.037 & $(0.023)$ & -0.038 & $(0.023)$ & $-0.049 * *$ & $(0.024)$ \\
\hline Age & & & & & -0.018 & $(0.053)$ & -0.025 & $(0.049)$ & -0.028 & $(0.053)$ & -0.017 & $(0.052)$ \\
\hline Age squared & & & & & 0.000 & $(0.001)$ & 0.001 & $(0.001)$ & 0.001 & $(0.001)$ & 0.001 & $(0.001)$ \\
\hline Chronic illness & & & & & -0.020 & $(0.022)$ & -0.022 & $(0.018)$ & -0.022 & $(0.018)$ & -0.023 & $(0.019)$ \\
\hline Currently working & & & & & $0.039 *$ & $(0.023)$ & $0.042 * *$ & $(0.020)$ & $0.042 * *$ & $(0.020)$ & $0.044 * *$ & $(0.021)$ \\
\hline Number of children & & & & & & & $-0.037 * *$ & $(0.015)$ & $-0.037 * *$ & $(0.015)$ & $-0.040 * * *$ & $(0.015)$ \\
\hline Number of elders & & & & & & & -0.043 & $(0.034)$ & -0.043 & $(0.034)$ & -0.037 & $(0.034)$ \\
\hline Number of working age members & & & & & & & $0.026 * * *$ & $(0.008)$ & $0.026 * * *$ & $(0.008)$ & $0.023 * * *$ & $(0.009)$ \\
\hline Education ratio of the couple: female / (male + female) & & & & & & & $-0.462 * * *$ & $(0.085)$ & $-0.463 * * *$ & $(0.085)$ & $-0.459 * * *$ & $(0.086)$ \\
\hline Fertile female ratio (women aged $18 / 45$ respect to males aged $18 / 65$ ) & & & & & & & -0.081 & $(0.097)$ & -0.082 & $(0.097)$ & $-0.203 * *$ & $(0.100)$ \\
\hline Age in wave $\mathrm{V}$ & & & & & & & & & 0.001 & $(0.008)$ & -0.000 & $(0.009)$ \\
\hline region: Northern and North Western & & & & & & & & & & & 0.048 & $(0.064)$ \\
\hline region: Central and Central Black-Earth & & & & & & & & & & & -0.057 & $(0.057)$ \\
\hline region: Volga-Vaytski and Volga Basin & & & & & & & & & & & 0.028 & $(0.057)$ \\
\hline region: North Caucasian & & & & & & & & & & & 0.050 & $(0.061)$ \\
\hline region: Ural & & & & & & & & & & & 0.012 & $(0.056)$ \\
\hline region: Western Siberian & & & & & & & & & & & 0.074 & $(0.061)$ \\
\hline and Far Eastern & & & & & & & & & & & 0.022 & $(0.059)$ \\
\hline Non-Russian nationality & & & & & & & & & & & -0.018 & $(0.035)$ \\
\hline Change in female participation to the labour market & & & & & & & & & & & -0.023 & $(0.068)$ \\
\hline Change in male participation to the labour market & & & & & & & & & & & -0.057 & $(0.066)$ \\
\hline Constant & $0.542 * * *$ & $(0.078)$ & $0.650 * * *$ & $(0.090)$ & 0.850 & $(0.650)$ & $1.124 *$ & $(0.589)$ & $1.156^{*}$ & $(0.632)$ & $1.174 *$ & $(0.620)$ \\
\hline $\mathrm{R}$-sq & 0.027 & & 0.047 & & 0.061 & & 0.147 & & 0.147 & & 0.194 & \\
\hline Observations & 645 & & 645 & & 645 & & 588 & & 588 & & 588 & \\
\hline Number of individuals & 265 & & 265 & & 265 & & 236 & & 236 & & 236 & \\
\hline
\end{tabular}

Cluster robust standard errors in parentheses

$* * * \mathrm{p}<0.01, * * \mathrm{p}<0.05, * \mathrm{p}<0.1$ 


\begin{tabular}{|c|c|c|c|c|c|c|c|c|c|c|}
\hline & \multicolumn{2}{|c|}{ Mod. 7: RE + sel } & \multicolumn{2}{|c|}{ Mod. 8: Mundlak + sel. } & \multicolumn{2}{|c|}{ Mod. 9: Tobit + sel. } & \multicolumn{2}{|c|}{ Mod. 10: Mund. Tobit + sel. } & \multicolumn{2}{|c|}{ Selection eq. ${ }^{1}$} \\
\hline & coef & se & coef & se & coef & se & coef & se & coef & se \\
\hline Mother's share of housework in waves V-VIII & $0.176 * *$ & $(0.077)$ & $0.164 * *$ & $(0.077)$ & $0.309 * * *$ & $(0.105)$ & $0.292 * * *$ & $(0.106)$ & & \\
\hline Average weekly hours of housework in waves V-VIII & 0.007 & $(0.006)$ & 0.005 & $(0.006)$ & 0.012 & $(0.009)$ & 0.009 & $(0.009)$ & & \\
\hline Per adult hours of housework in the family of origin & -0.000 & $(0.001)$ & -0.000 & $(0.001)$ & -0.001 & $(0.001)$ & -0.000 & $(0.001)$ & & \\
\hline Average father's work status in waves V-VIII (in each wave 1=work) & 0.622 & $(0.036)$ & -0.049 & $(0.035)$ & $-0.096^{*}$ & $(0.053)$ & 0.474 & $(0.052)$ & 0.629 & $(0.441)$ \\
\hline Average mother's work status in waves V-VIII (in each wave 1=work) & 0.097 & $(0.031)$ & -0.020 & $(0.031)$ & 0.039 & $(0.374)$ & 0.082 & $(0.045)$ & -0.040 & $(0.045)$ \\
\hline Mother's highest completed grade is in primary education & -0.003 & $(0.045)$ & -0.030 & $(0.600)$ & -0.014 & $(0.067)$ & $1.238^{* *}$ & $(0.069)$ & $1.181 * *$ & $(0.600)$ \\
\hline Father's highest completed grade is in primary education & $0.614 * *$ & $(0.300)$ & 0.007 & $(0.293)$ & 0.001 & $(0.035)$ & $0.545^{*}$ & $(0.035)$ & $0.573 *$ & $(0.300)$ \\
\hline Mother's highest completed grade is in tertiary education & -0.093 & $(0.311)$ & -0.018 & $(0.025)$ & -0.012 & $(0.312)$ & -0.003 & $(0.305)$ & -0.107 & $(0.034)$ \\
\hline Father's highest completed grade is in tertiary education & -0.365 & $(0.026)$ & 0.014 & $(0.026)$ & 0.032 & $(0.037)$ & -0.196 & $(0.338)$ & -0.315 & $(0.342)$ \\
\hline Gender $(1=$ male $)$ & $-0.879 * * *$ & $(0.021)$ & $-0.039 *$ & $(0.022)$ & $-0.876 * * *$ & $(0.033)$ & $-0.834 * * *$ & $(0.248)$ & -0.042 & $(0.249)$ \\
\hline Age & $1.898 * * *$ & $(0.052)$ & 0.027 & $(0.068)$ & $1.965 * * *$ & $(0.079)$ & -0.036 & $(0.100)$ & -0.093 & $(0.430)$ \\
\hline Age squared & $-0.036 * * *$ & $(0.001)$ & -0.000 & $(0.010)$ & $-0.037 * * *$ & $(0.009)$ & $-0.047 * * *$ & $(0.002)$ & 0.002 & $(0.002)$ \\
\hline Chronic illness & 0.099 & $(0.161)$ & 0.018 & $(0.027)$ & 0.052 & $(0.162)$ & 0.027 & $(0.036)$ & $-0.044 *$ & $(0.025)$ \\
\hline Currently working & $-0.295 * *$ & $(0.145)$ & $0.059 * * *$ & $(0.022)$ & $-0.325 * *$ & $(0.145)$ & $-0.413 * *$ & $(0.030)$ & $0.050 * *$ & $(0.025)$ \\
\hline Number of children & $-0.028 *$ & $(0.015)$ & $-0.083^{* * *}$ & $(0.025)$ & $-0.062 * * *$ & $(0.020)$ & $-0.116^{* * *}$ & $(0.032)$ & & \\
\hline Number of elders & -0.027 & $(0.026)$ & -0.016 & $(0.031)$ & -0.040 & $(0.035)$ & -0.018 & $(0.042)$ & & \\
\hline Number of working age members & $0.024 * * *$ & $(0.007)$ & $0.030 * * *$ & $(0.010)$ & $0.025 * * *$ & $(0.009)$ & $0.027 * *$ & $(0.013)$ & & \\
\hline Education ratio of the couple: female / (male + female) & $-0.497 * * *$ & $(0.060)$ & $-0.579 * * *$ & $(0.092)$ & $-0.845^{* * *}$ & $(0.100)$ & $-1.145^{* * *}$ & $(0.161)$ & & \\
\hline Fertile female ratio (women aged $18 / 45$ respect to males aged $18 / 65$ ) & $-0.189 * *$ & $(0.090)$ & 0.105 & $(0.151)$ & $-0.339 * * *$ & $(0.122)$ & 0.053 & $(0.202)$ & & \\
\hline Age in wave $\mathrm{V}$ & 0.004 & $(0.074)$ & 0.015 & $(0.025)$ & -0.012 & $(0.075)$ & 0.017 & $(0.035)$ & $0.422 * * *$ & $(0.012)$ \\
\hline region: Northern and North Western & 0.028 & $(0.060)$ & 0.045 & $(0.060)$ & 0.040 & $(0.085)$ & 0.065 & $(0.085)$ & 0.060 & $(0.763)$ \\
\hline region: Central and Central Black-Earth & -0.048 & $(0.049)$ & -0.056 & $(0.049)$ & $-0.127 *$ & $(0.639)$ & $-0.121^{*}$ & $(0.071)$ & 0.362 & $(0.072)$ \\
\hline region: Volga-Vaytski and Volga Basin & 0.184 & $(0.661)$ & 0.026 & $(0.049)$ & 0.254 & $(0.072)$ & 0.155 & $(0.071)$ & 0.004 & $(0.661)$ \\
\hline region: North Caucasian & -0.633 & $(0.681)$ & 0.048 & $(0.669)$ & 0.067 & $(0.075)$ & -0.426 & $(0.076)$ & -0.507 & $(0.682)$ \\
\hline region: Ural & -0.278 & $(0.665)$ & 0.025 & $(0.049)$ & -0.214 & $(0.071)$ & -0.220 & $(0.070)$ & -0.015 & $(0.665)$ \\
\hline region: Western Siberian & 0.064 & $(0.054)$ & 0.075 & $(0.053)$ & 0.450 & $(0.077)$ & 0.087 & $(0.711)$ & 0.056 & $(0.713)$ \\
\hline region: Eastern Siberian and Far Eastern & 0.023 & $(0.056)$ & 0.009 & $(0.718)$ & 0.006 & $(0.079)$ & -0.675 & $(0.078)$ & -0.517 & $(0.728)$ \\
\hline Non-Russian nationality & -0.030 & $(0.030)$ & -0.028 & $(0.267)$ & -0.054 & $(0.270)$ & -0.046 & $(0.272)$ & 0.105 & $(0.042)$ \\
\hline Change in female participation to the labour market & $-1.195 * *$ & $(0.561)$ & 0.001 & $(0.062)$ & 0.017 & $(0.089)$ & 0.044 & $(0.089)$ & $-1.014 *$ & $(0.560)$ \\
\hline Change in male participation to the labour market & $1.192 *$ & $(0.656)$ & -0.052 & $(0.071)$ & $1.115^{*}$ & $(0.104)$ & -0.164 & $(0.103)$ & $-0.174 *$ & $(0.644)$ \\
\hline Longitudinal average of: Age & & & -0.077 & $(0.091)$ & & & -0.075 & $(0.128)$ & & \\
\hline Longitudinal average of: Age squared & & & 0.001 & $(0.002)$ & & & 0.001 & $(0.003)$ & & \\
\hline
\end{tabular}


Longitudinal average of: Chronic illness

Longitudinal average of: Currently working

Longitudinal average of: Number of children

Longitudinal average of: Number of elders

Longitudinal average of: Number of working age members

Longitudinal average of: Education ratio of the couple

Longitudinal average of: Fertile female ratio

\section{BMI z-score}

Average age at marriage (by PSU in 2000-2012)

Standard deviation of age at marriage (by PSU in 2000-2012)

Father economic status

Mother economic status

Constant

$\sigma_{\alpha}$

$\sigma_{\varepsilon}$

$\sigma_{v}$

$\sigma_{\epsilon}$

$\rho_{\alpha v}$

$\rho_{\varepsilon \epsilon}$

Pseudo R-squared

Observations

Number of individuals

Cluster robust standard errors in parenthese

$* * * p<0.01, * * p<0.05, * p<0.1$

$\begin{array}{cc}-0.060 * & (0.036) \\ -0.045 & (0.036) \\ 0.088 * * * & (0.032) \\ -0.040 & (0.044) \\ -0.016 & (0.014) \\ 0.125 & (0.120) \\ -0.437 * * & (0.190)\end{array}$

$-0.078$

$-0.094 *$

$0.094 * *$

$-0.047$

$-0.004$

$0.469 * *$

$-0.567 * *$

$(0.051)$

$(0.051)$

$(0.043)$

$(0.060)$

(0.019)

$(0.194)$

$(0.256)$

$0.183 * *$

$-0.353 * * * \quad(0.124)$

$0.196 * * \quad(0.086)$

$0.061 \quad(0.150)$

$\begin{array}{cc}0.111 & (0.148) \\ 2.702 * * * & (1.037)\end{array}$

$2.521 \quad(0.226)$

$\begin{array}{llllll}0.099 & (0.012) & 0.094 & (0.011) & 0.140 & (0.021) \\ 0.159 & (0.006) & 0.157 & (0.006) & 0.201 & (0.013)\end{array}$

$\begin{array}{lllll}(0.006) & 0.157 & (0.006) & 0.201 & (0.013)\end{array}$

$\begin{array}{llllll}0.365 & (0.160) & 0.282 & (0.172) & -0.359 & (0.287)\end{array}$

$\begin{array}{llllll}-0.147 & (0.096) & -0.119 & (0.097) & -0.758 & (0.236)\end{array}$

$\begin{array}{llll}0.258 & 0.281 & 0.209 & 0.227\end{array}$

$\begin{array}{lrrr}588 & 588 & 588 & 588\end{array}$

236

236 


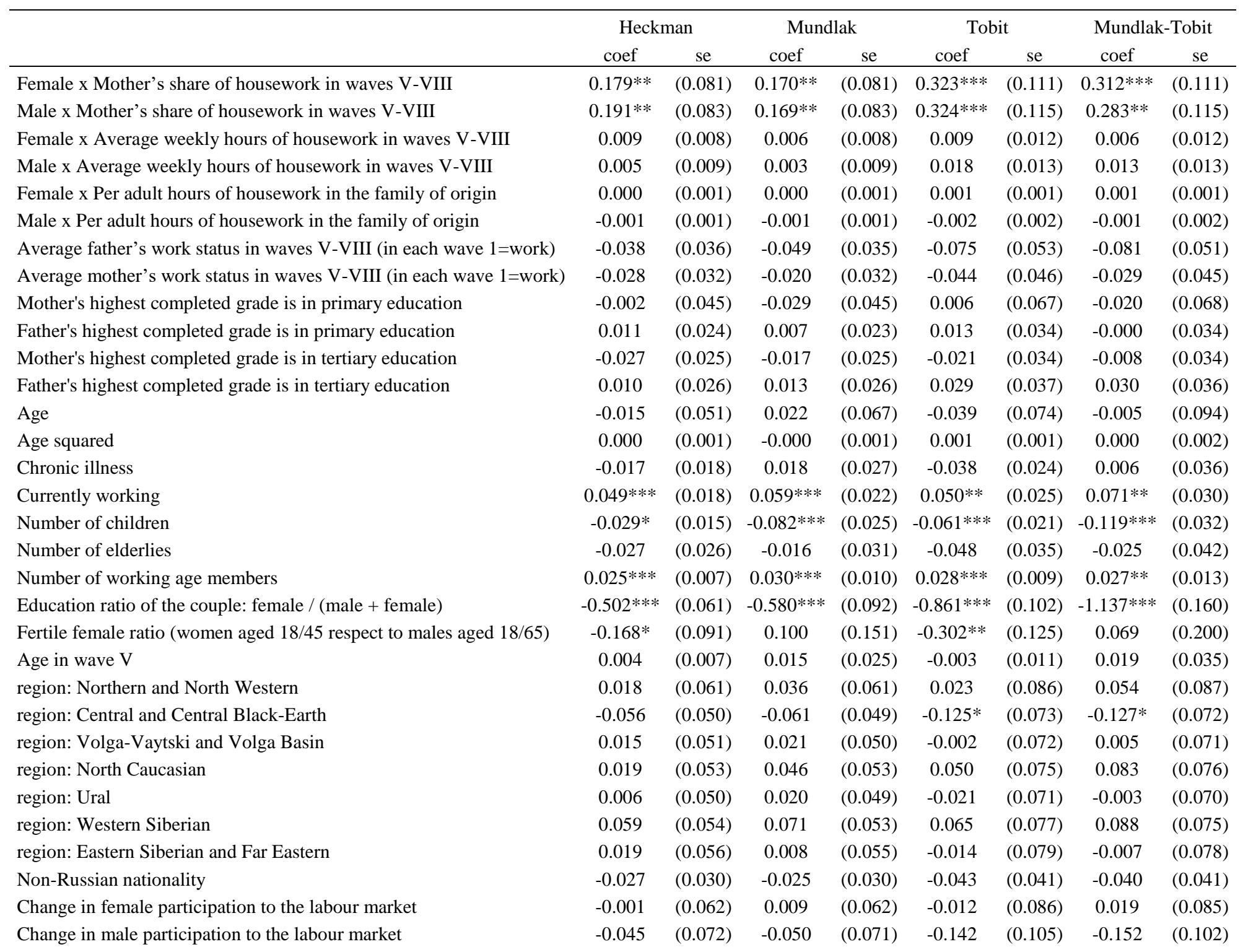


Longitudinal average of: Age

Longitudinal average of: Age squared

Longitudinal average of: Chronic illness

Longitudinal average of: Currently working

Longitudinal average of: Number of children

Longitudinal average of: Number of elderlies

Longitudinal average of: Number of working age members

Longitudinal average of: Education ratio of the couple

Longitudinal average of: Fertile female ratio

Constant

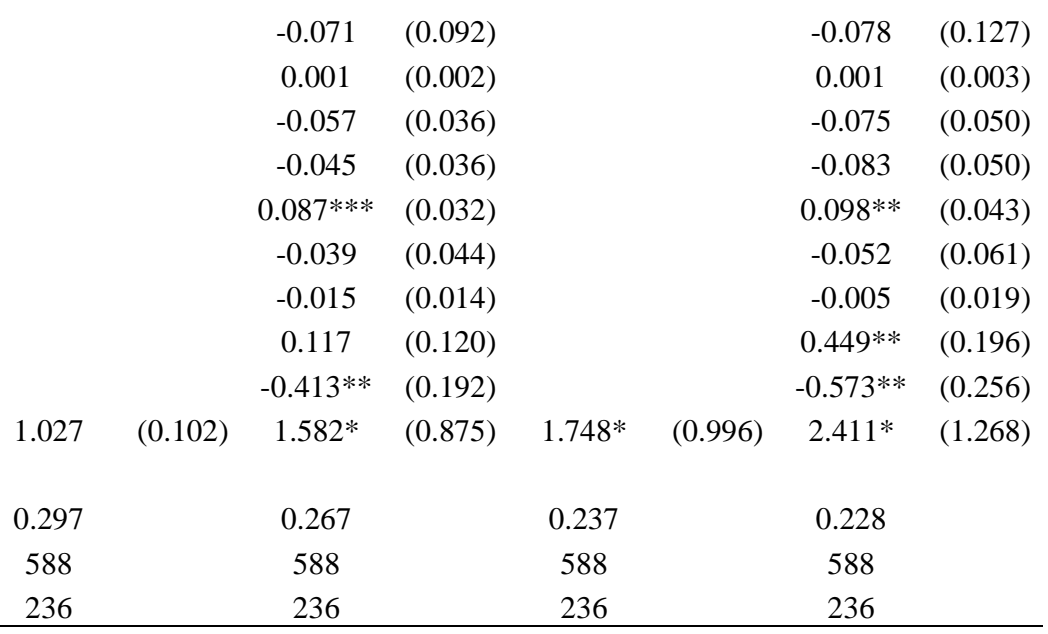

Pseudo R-squared ${ }^{1}$

Observations

236

236

Notes: 1. The pseudo R-squared of linear and Tobit specifications cannot be compared as the likelihood function is different.

Cluster robust standard errors in parentheses

$* * * \mathrm{p}<0.01, * * \mathrm{p}<0.05, * \mathrm{p}<0.1$ 
Table A.5: Specification tests

\begin{tabular}{lccc}
\hline Specification test & $\mathrm{X}^{2}$ & Df & P-val \\
\hline 1) Linear RE vs OLS: $\operatorname{Var}(\alpha)=0$ & 27.18 & 1 & 0.000 \\
2) Mundlak vs Linear RE: all $\pi=0$ & 17.82 & 9 & 0.037 \\
3) RE Tobit vs Tobit: $\operatorname{Var}(\alpha)=0$ & 37.59 & 1 & 0.000 \\
4) Mundlak RE Tobit vs RE Tobit: all $\pi=0$ & 26.94 & 9 & 0.001 \\
5) RE + selection vs RE: $\rho_{\alpha v}=0$ and $\rho_{\varepsilon \epsilon}=0$ & 8.40 & 2 & 0.015 \\
6) By gender: likelihood ratio test & 77.36 & 29 & 0.000 \\
\hline
\end{tabular}

Notes. The table resumes several specification tests conducted to identify the more robust econometric specification. 1) Tests whether a linear RE model should be preferred to a pooled OLS estimation. This is performed by testing whether the variance of the individual effect $(\alpha)$ is significantly different from zero. The test strongly rejects the null of a variance equal to zero. 2) Tests whether the Mundlak extension to the RE should be preferred to a linear RE. This test is based on the null that the coefficients of the longitudinal mean variables, included in the Mundlak estimation by construction, are jointly equal from zero, which is rejected at a $5 \%$ significance level. 3) Verifies whether a RE Tobit specification should be preferred to a pooled Tobit, similar to 1), and again the null is strongly rejected. 4) is similar to 2) and tests whether the Mundlak extension applied to the RE Tobit specification should be preferred. The test strongly rejects the null that the coefficients of the longitudinal mean variables are jointly equal to zero. 5) Tests the selection into marriage, which is assumed to be at work if the correlation of the individual effects and idiosyncratic components of the two equations are jointly different from zero. Given that the coefficients of the three exclusion of the selection equations reported by Table A.3 are all significantly different from zero at least at a 5\% significance level, the test suggests that selection into marriage is at work. 6) Tests, using a likelihood ratio test, whether a specification with the coefficients of the variables of interest differentiated by gender is statistically superior, which is indeed confirmed. 
Table A6: Weekly hours spent on domestic work and specific activities - Full estimations.

\begin{tabular}{|c|c|c|c|c|c|c|c|c|c|c|}
\hline & \multicolumn{2}{|c|}{ Domestic work } & \multicolumn{2}{|c|}{ Purch. food } & \multicolumn{2}{|c|}{ Cooking } & \multicolumn{2}{|c|}{ Cleaning } & \multicolumn{2}{|c|}{ Laundry } \\
\hline & coef & se & coef & se & coef & se & coef & se & coef & se \\
\hline Female $\mathrm{x}$ Mother share of traditional domestic work in waves V-VIII & 2.011 & $(3.598)$ & $1.069 * *$ & $(0.426)$ & 1.197 & $(0.994)$ & 0.825 & $(0.644)$ & 1.296 & $(0.983)$ \\
\hline Male $\mathrm{x}$ Mother share of traditional domestic work in waves V-VIII & $-12.17 * * *$ & $(3.729)$ & 0.676 & $(0.491)$ & $-6.213^{* * *}$ & $(1.220)$ & $-2.389 * * *$ & $(0.781)$ & $-6.891 * * *$ & $(1.337)$ \\
\hline Female x Average weekly hours of domestic work in waves V-VIII & 0.405 & $(0.358)$ & $0.138^{*}$ & $(0.079)$ & 0.235 & $(0.143)$ & $0.223 * *$ & $(0.104)$ & $0.320 * * *$ & $(0.105)$ \\
\hline Male x Average weekly hours of domestic work in waves V-VIII & -0.541 & $(0.434)$ & -0.119 & $(0.117)$ & 0.259 & $(0.218)$ & -0.087 & $(0.171)$ & -0.016 & $(0.231)$ \\
\hline Female $x$ Per-adult hours of domestic work in the family of origin & 0.062 & $(0.041)$ & 0.014 & $(0.008)$ & 0.019 & $(0.015)$ & -0.001 & $(0.011)$ & -0.001 & $(0.011)$ \\
\hline Male $\mathrm{x}$ Per-adult hours of domestic work in the family of origin & -0.017 & $(0.052)$ & -0.006 & $(0.012)$ & $-0.062 * *$ & $(0.025)$ & $-0.057 * * *$ & $(0.019)$ & 0.021 & $(0.024)$ \\
\hline Average father's work status in waves V-VIII (in each wave $1=$ =work) & 1.176 & $(1.689)$ & $0.469^{*}$ & $(0.284)$ & 0.635 & $(0.521)$ & 0.241 & $(0.385)$ & -0.082 & $(0.433)$ \\
\hline Average mother's work status in waves V-VIII (in each wave $1=$ work) & $-2.736 *$ & $(1.472)$ & $-0.678 * *$ & $(0.335)$ & $-2.056^{* * * *}$ & $(0.609)$ & $-1.578 * * *$ & $(0.443)$ & $-1.531 * * *$ & $(0.472)$ \\
\hline Mother's highest completed grade is in primary education & 1.781 & $(2.221)$ & 0.674 & $(0.567)$ & -0.148 & $(1.046)$ & -1.151 & $(0.770)$ & 0.008 & $(0.801)$ \\
\hline Father's highest completed grade is in primary education & 0.384 & $(1.090)$ & 0.075 & $(0.283)$ & 0.031 & $(0.519)$ & 0.235 & $(0.380)$ & -0.038 & $(0.397)$ \\
\hline Mother's highest completed grade is in tertiary education & 1.082 & (1.118) & 0.193 & $(0.273)$ & 0.168 & $(0.499)$ & 0.461 & $(0.369)$ & 0.070 & $(0.396)$ \\
\hline Father's highest completed grade is in tertiary education & -1.270 & $(1.161)$ & -0.255 & $(0.307)$ & $-0.926^{*}$ & $(0.562)$ & -0.395 & $(0.406)$ & -0.302 & $(0.436)$ \\
\hline Age & -1.325 & (3.456) & -0.637 & (1.005) & -1.311 & $(1.852)$ & -0.609 & $(1.351)$ & -0.689 & $(1.440)$ \\
\hline Age squared & 0.028 & $(0.069)$ & 0.014 & $(0.020)$ & 0.028 & $(0.038)$ & 0.014 & $(0.027)$ & 0.015 & $(0.029)$ \\
\hline Chronic illness & 0.533 & $(1.323)$ & 0.172 & $(0.405)$ & 0.429 & $(0.740)$ & 0.086 & $(0.546)$ & $1.213^{* *}$ & $(0.581)$ \\
\hline Currently working & $9.678 * * *$ & (1.132) & $1.770 * * *$ & $(0.340)$ & $4.382 * * *$ & $(0.623)$ & $1.368 * * *$ & $(0.455)$ & $1.865 * * *$ & $(0.478)$ \\
\hline Number of children & -0.571 & (1.214) & -0.365 & $(0.383)$ & -0.282 & $(0.720)$ & -0.169 & $(0.531)$ & 0.522 & $(0.586)$ \\
\hline Number of elders & -0.201 & $(1.546)$ & -0.191 & $(0.467)$ & -1.106 & $(0.896)$ & 0.190 & $(0.636)$ & 0.393 & $(0.728)$ \\
\hline Number of working age members & -0.253 & $(0.481)$ & -0.211 & $(0.142)$ & -0.099 & $(0.272)$ & -0.089 & $(0.200)$ & -0.096 & $(0.228)$ \\
\hline Education ratio of the couple: female / (male + female) & -1.194 & $(4.449)$ & 0.643 & $(1.250)$ & 1.262 & $(2.298)$ & -0.128 & $(1.706)$ & 2.582 & $(1.738)$ \\
\hline Fertile female ratio (women aged $18 / 45$ respect to males aged $18 / 65$ ) & $14.436^{*}$ & $(7.441)$ & -0.569 & $(2.215)$ & 4.535 & $(4.062)$ & 1.210 & $(2.972)$ & 0.052 & $(3.156)$ \\
\hline Age in wave $\mathrm{V}$ & -1.461 & $(1.182)$ & -0.413 & $(0.298)$ & $-1.077 *$ & $(0.562)$ & -0.487 & $(0.412)$ & $-0.915 * *$ & $(0.443)$ \\
\hline Region: Northern and North Western & -3.449 & $(2.856)$ & $-2.616 * * *$ & $(0.693)$ & 0.210 & $(1.290)$ & -0.861 & $(0.947)$ & $1.796^{*}$ & $(1.078)$ \\
\hline Region: Central and Central Black-Earth & -1.315 & $(2.366)$ & $-1.554 * * *$ & $(0.588)$ & 1.079 & $(1.105)$ & -1.003 & $(0.809)$ & 0.317 & $(0.958)$ \\
\hline Region: Volga-Vaytski and Volga Basin & -1.007 & $(2.349)$ & $-1.636 * * *$ & $(0.586)$ & 0.137 & $(1.107)$ & -1.304 & $(0.813)$ & 0.208 & $(0.968)$ \\
\hline Region: North Caucasian & -3.147 & $(2.476)$ & $-2.254 * * *$ & $(0.618)$ & -1.121 & $(1.171)$ & $-1.723 * *$ & $(0.862)$ & -0.688 & $(1.027)$ \\
\hline Region: Ural & -2.786 & $(2.309)$ & $-2.265^{* * *}$ & $(0.583)$ & 0.393 & $(1.098)$ & -0.909 & $(0.800)$ & 0.870 & $(0.951)$ \\
\hline Region: Western Siberian & -3.340 & $(2.491)$ & $-1.885^{* * *}$ & $(0.623)$ & -1.495 & $(1.176)$ & -0.783 & $(0.852)$ & 1.012 & $(0.998)$ \\
\hline Region: Eastern Siberian and Far Eastern & $-5.018 * *$ & $(2.535)$ & $-2.630 * * *$ & $(0.644)$ & -0.615 & $(1.209)$ & $-1.895 * *$ & $(0.884)$ & 0.235 & $(1.028)$ \\
\hline Non-Russian nationality & -1.511 & $(1.437)$ & 0.110 & $(0.440)$ & -1.281 & $(0.824)$ & $-1.227 * *$ & $(0.603)$ & -0.411 & $(0.647)$ \\
\hline Change in female participation to the labour market & 1.010 & $(2.878)$ & -0.347 & $(0.728)$ & -0.830 & $(1.356)$ & 0.067 & $(1.004)$ & -1.707 & $(1.098)$ \\
\hline Change in male participation to the labour market & $-5.946 *$ & $(3.475)$ & 1.150 & $(0.936)$ & $-3.276^{*}$ & $(1.735)$ & -1.525 & $(1.262)$ & -0.876 & $(1.381)$ \\
\hline
\end{tabular}


Longitudinal average of: Age

Longitudinal average of: Age squared

Longitudinal average of: Chronic illness

Longitudinal average of: Currently working

Longitudinal average of: Number of children

Longitudinal average of: Number of elders

Longitudinal average of: Number of working age members

Longitudinal average of: Education ratio of the couple

Longitudinal average of: Fertile female ratio

Constant

Pseudo R-squared ${ }^{1}$

Observations

Number of individuals

Cluster robust standard errors in parentheses

$* * * \mathrm{p}<0.01, * * \mathrm{p}<0.05, * \mathrm{p}<0.1$

\begin{tabular}{|c|c|c|c|c|c|c|c|c|c|}
\hline 3.321 & $(4.432)$ & 1.899 & $(1.232)$ & 2.145 & $(2.262)$ & 2.046 & (1.662) & 1.833 & (1.771) \\
\hline-0.037 & $(0.087)$ & -0.034 & $(0.024)$ & -0.021 & $(0.045)$ & -0.035 & $(0.033)$ & -0.021 & $(0.035)$ \\
\hline 0.063 & $(1.757)$ & -0.278 & $(0.494)$ & 0.372 & (0.904) & 0.252 & $(0.665)$ & $-1.235^{*}$ & (0.709) \\
\hline-1.153 & $(1.722)$ & -0.162 & $(0.467)$ & -0.760 & $(0.858)$ & -0.103 & $(0.624)$ & -0.332 & $(0.650)$ \\
\hline-0.194 & (1.509) & -0.152 & $(0.440)$ & -0.073 & (0.823) & -0.558 & $(0.607)$ & -0.763 & $(0.666)$ \\
\hline-1.530 & $(2.154)$ & 0.507 & $(0.547)$ & 0.034 & (1.035) & -0.122 & $(0.745)$ & -0.161 & $(0.831)$ \\
\hline-0.864 & (0.674) & 0.007 & $(0.184)$ & $-0.642 *$ & $(0.350)$ & -0.162 & $(0.257)$ & -0.319 & $(0.295)$ \\
\hline 1.332 & (5.766) & -0.887 & (1.541) & 0.599 & (2.833) & -0.205 & $(2.092)$ & -0.457 & $(2.161)$ \\
\hline-6.810 & (9.111) & $5.293 * *$ & $(2.522)$ & 0.983 & (4.660) & 1.946 & (3.394) & -1.366 & (3.594) \\
\hline-10.618 & (42.234) & -13.876 & (9.609) & -3.641 & (17.637) & -11.662 & (12.960) & -7.172 & (13.551) \\
\hline \multicolumn{2}{|c|}{0.098} & \multicolumn{8}{|c|}{0.368} \\
\hline \multicolumn{2}{|c|}{588} & \multicolumn{8}{|c|}{579} \\
\hline \multicolumn{2}{|c|}{236} & \multicolumn{8}{|c|}{235} \\
\hline
\end{tabular}

